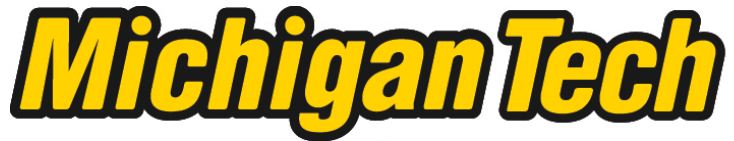 \\ Michigan Technological University Create the Future Digital Commons @ Michigan Tech
}

Dissertations, Master's Theses and Master's Reports - Open

Dissertations, Master's Theses and Master's

Reports

2011

Characterisation of the metacaspase gene family in Arabidopsis thaliana

Paige N. Cox

Michigan Technological University

Follow this and additional works at: https://digitalcommons.mtu.edu/etds

Part of the Forest Sciences Commons

Copyright 2011 Paige N. Cox

\section{Recommended Citation}

Cox, Paige N., "Characterisation of the metacaspase gene family in Arabidopsis thaliana", Master's Thesis, Michigan Technological University, 2011.

https://doi.org/10.37099/mtu.dc.etds/147

Follow this and additional works at: https://digitalcommons.mtu.edu/etds

Part of the Forest Sciences Commons 


\title{
CHARACTERISATION OF THE METACASPASE GENE FAMILY IN ARABIDOPSIS THALIANA
}

\author{
By \\ Paige N. Cox \\ A THESIS \\ Submitted in partial fulfilment of the requirements for the degree of \\ MASTER OF SCIENCE
}

Forest Molecular Genetics and Biotechnology

MICHIGAN TECHNOLOGICAL UNIVERSITY

2011

(C) 2011 Paige N. Cox 
This thesis, "Characterisation of the metacaspase gene family in Arabidopsis thaliana" is hereby approved in partial fulfilment of the requirements for the Degree of MASTER OF SCIENCE IN FOREST MOLECULAR GENETICS AND BIOTECHNOLOGY.

School of Forest Resources and Environmental Science

Signatures:

Thesis Advisor

Hannele Tuominen

Thesis Co-Adviser

Victor Busov

Dean

Peg Gale

Date 


\section{Table of Contents}

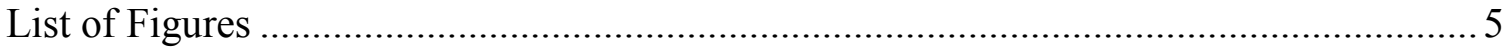

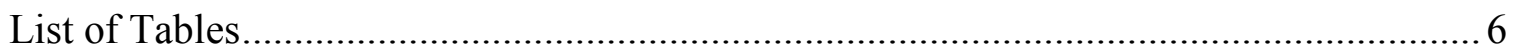

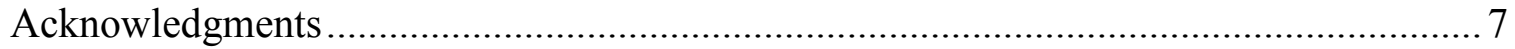

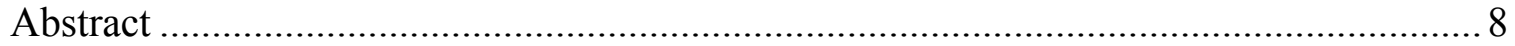

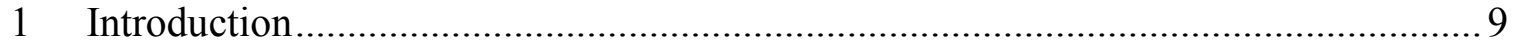

1.1 Introduction to the components of programmed cell death...........................................9

1.1.1 Introduction to Programmed Cell Death ...............................................................

1.1.2 Enzymes Involved in PCD ..........................................................................

1.1.3 Caspases and Proteins with Caspase-like activity .................................................10

1.1.4 Introduction to Metacaspases ............................................................................11

1.1.5 Similarities and differences between caspases, and MCs …………………........12

$1.2 \quad$ Analysis of MC Functions.....................................................................................13

1.2.1 Enzyme activity and substrate/inhibitor analyses.................................................13

1.2.2 Developmental Functional characterisation .........................................................16

1.3 My Thesis: The value in determining the function of MC genes and their connection to

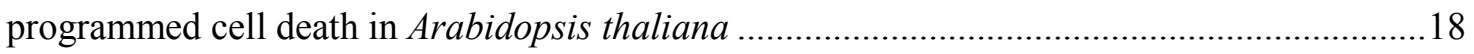

1.3.1 Value of the project......................................................................................

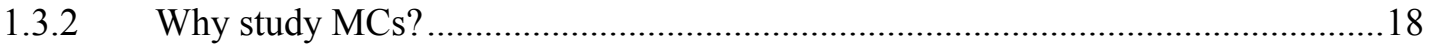

1.3.3 Objectives and goals of the thesis ................................................................19

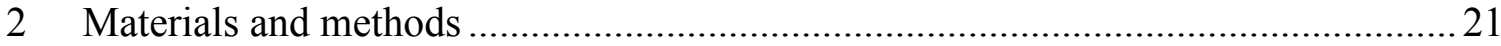

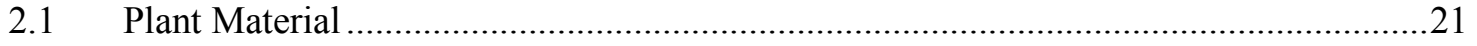

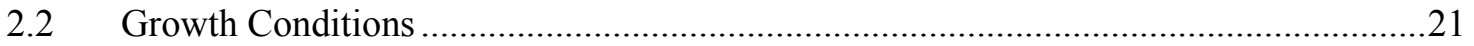

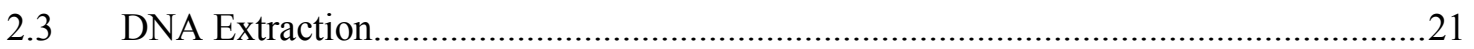

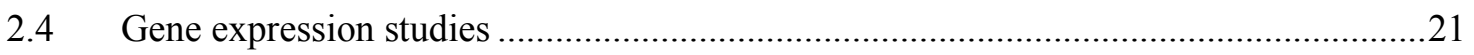

2.5 GUS histochemical staining ...........................................................................2

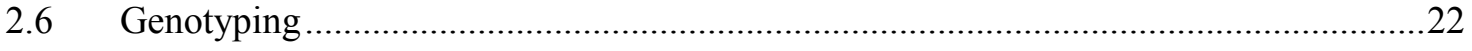

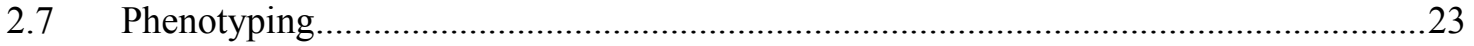

2.7.1 Mutants and experimental design ...................................................................23

2.7.2 Phenotyping Data Collection..............................................................................24 


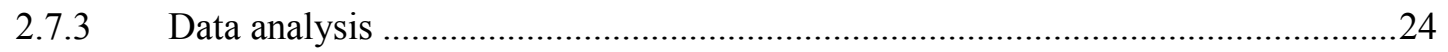

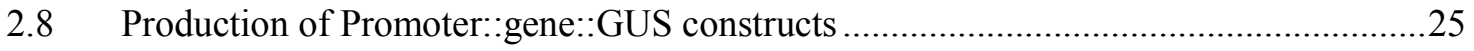

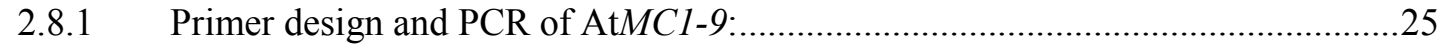

2.8.2 Production of constructs using Gateway ${ }^{\circledR}$ cloning ..............................................26

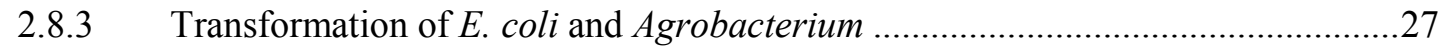

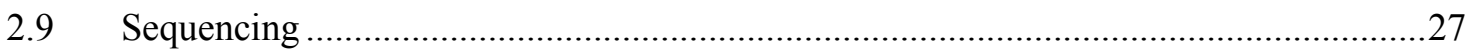

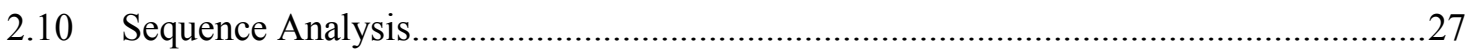

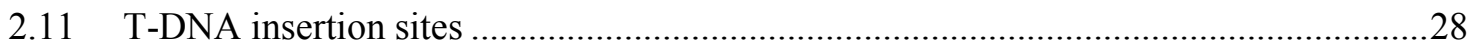

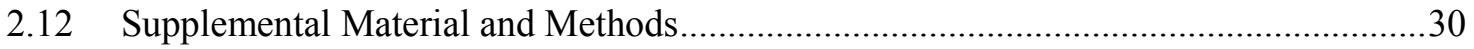

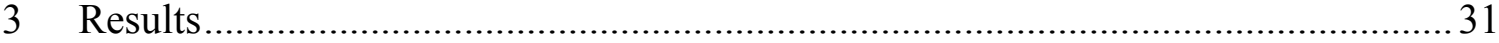

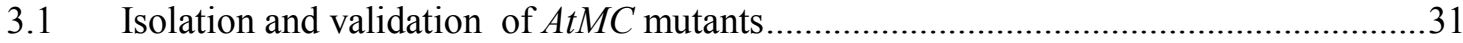

3.2 In silico expression analysis of the AtMC gene family ..............................................

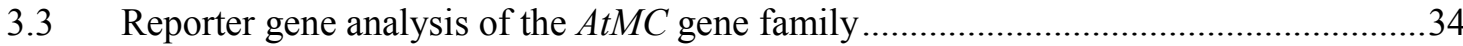

3.4 Functional characterization of the AtMC gene family by reverse genetic approaches...35

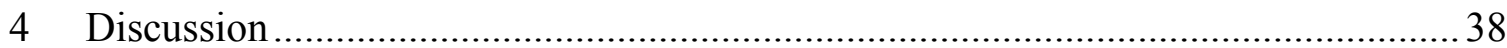

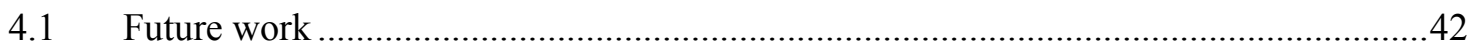

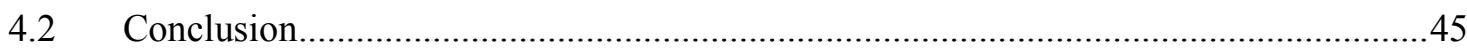

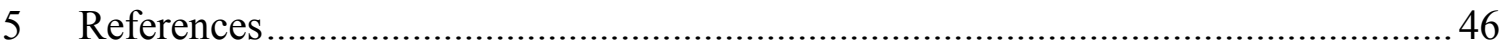




\section{List of Figures}

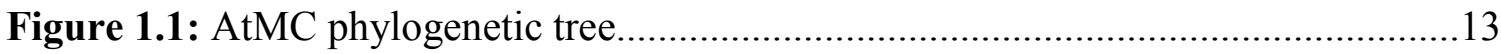

Figure 2.1: Schematic representation of the DNA insertion sites for all AtMCs............29

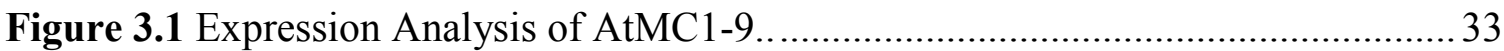

Figure 3.2: Expression of promoter::gene::GUS constructs in Arabidopsis.................... 34

Figure 3.3: Morphological changes in AtMC single and double mutants..................... 37 


\section{List of Tables}

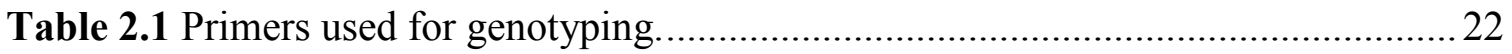

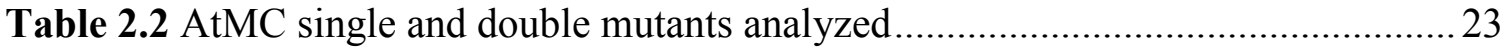

Table 2.3 Forward, reverse and inset primer sequences............................................ 25

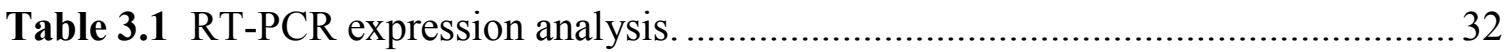

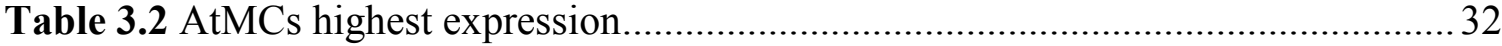

Table 3.3 Mutant lines with statistically significant differences .................................. 35 


\section{Acknowledgments}

First and foremost I would like to give a special thank you to my family and friends. These are the people who I can always count on to make me laugh when I need a pickme-up, who have inspired me to become a better person, and who I have come to treasure over the years for each of their unique personalities. Without the support of these people, I would not be who I am, or have made it to where I am, today.

Secondly, I would like to thank my adviser at the Umeå Plant Science Centre in Umeå Sweden, Hannele Tuominen, for accepting me as her Master's student. She was a joy to work with and has been a wonderful inspiration and role model both in science and in life. Her guidance and encouragement have been invaluable throughout my whole Master's degree process, and I am extremely proud to have worked with her and learned from her.

Another role model I am honoured to have met during my academic career is my Michigan Tech co-adviser, Victor Busov. I would first like to thank him for providing me with the initial opportunity to work in his lab, an opportunity which helped me to find my direction in life, and for helping to further encourage my future scientific aspirations and career. Victor supported me during the hardest moments of this thesis and I will never forget his kindness.

Also deserving of acknowledgment are my committee members, Shekhar Joshi and Rupali Datta who helped to make the defence a more enjoyable event than it could have been, and for all of their helpful comments regarding my thesis. Thank you, as well, to Andreas Artemiou for assistance with the statistical analysis, and to Blair Orr for introducing me to Michigan Technological University.

To the sponsors of the ATLANTIS program, I also show my appreciation for financially supporting my stay in Sweden and Finland and to Shekhar Joshi, Karin Ljung and Maija Kovanen, for all their hard work in coordinating the program in USA/Sweden/Finland.

Thank you to all the other MS, PhD, Post Doctorial, and professors both in Sweden and in the US who have helped to make this journey so pleasant and delightful, all the while providing me with the knowledge needed to successfully complete this degree. These people include, but are certainly not limited to: Benjamin Bollhöner, Jakob Prestele, Bo Zhang, Sacha Escamez, Maria Lundström, Veronica Bourquin, and Yiru Chen.

Finally, thank you to Robert Swanson for sparking my fascination with plant biology and scientific research. His contagious enthusiasm has ultimately resulted in my current passion toward this field of biology. 


\section{Abstract}

Caspases are known to be involved in animal programmed cell death (PCD). The objective of this thesis was to use gene expression analysis and reverse genetics to determine if Arabidopsis metacaspase (AtMC) genes play a role in plant PCD. The majority of $A t M C$ genes were found to be expressed nearly constitutively in various tissues, developmental stages, and under various inductive treatments. Transgenic Arabidopsis plants generated with AtMCpromoter::AtMCgene::GUS fusions showed expression of the reporter gene in leaves, vasculature, trichomes, siliques, anthers, and during embryo development. Preliminary phenotypic characterization of single and double Arabidopsis AtMC loss-of-function mutants suggested that the expression of the AtMC genes are highly functionally redundant. Nevertheless, our results suggest that AtMC1, 2, 4, 6 and 9 may be directly involved in rosette and/or stem development. Although this study does not provide a definitive role of MCs in plant PCD, it lays the foundation for their further in-depth analysis. 


\section{Introduction}

\subsection{Introduction to the components of programmed cell death}

\subsubsection{Introduction to Programmed Cell Death}

Programmed cell death (PCD), also known as apoptosis, is a process which maintains constant cell numbers during development through elimination of unwanted cells (Watanabe \& Lam 2005). PCD also creates structures entirely composed of dead cells, for example plant xylem treachery elements (TEs) which function in the transport of water and nutrients from the soil (Greenberg 1996, Cooper 2000). In animals, the active process of PCD is characterized by condensation of the chromatin, membrane blebbing, chromosomal DNA breakage, condensation of the cytoplasm, and fragmentation of the nucleus (Cooper 2000.) Several of these cellular events can be observed in plants as well. For example, plants also undergo cytosolic condensation, and fragmentation of the nucleus (Greenberg 1996, Woltering et al. 2004). However, in plants PCD is also associated with vacuolar collapse (Nieminen et al. 2004, Bonneau et al. 2008) which is especially important during PCD of TEs. Cell death is also important during plant reproduction, senescence, flowering, and defence against pathogens (Greenberg 1996). It has been suggested that PCD may be involved in self incompatibility responses (Bonneau et al. 2008, Love et al. 2008). PCD in plants is enabled by the proteases that can elicit, en masse, cellular proteolytic degradation. These enzymes and their function in plant development are the focus of this study.

\subsubsection{Enzymes Involved in PCD}

Protein degradation, or proteolysis, is the breakdown of proteins via cleavage by enzymes known as proteases. Cleavage can be a regulatory process which activates or inhibits protein activity, or can destroy it altogether. It is important in regulation of gene expression, in the cell cycle and in PCD (Sheth \& Yadlapati 2009). Proteases cleave the proteins' peptide bonds using hydrolysis. Each protease contains a catalytic diad or triad made up of two to three amino acids, plus a pocket ( $\mathrm{S}_{1}$ Pocket), which together creates the active site. The substrate binds to the pocket and the catalytic dyad/triad induces 
cleavage of the peptide. Water enters the active site and the part of the substrate still located inside the pocket is released (Cooper 2000).

Cells control protease activity and thus the amount and rate of PCD via protease inhibitors (Solomon et al. 1999). Two well known protease inhibitors are Inhibitors of Apoptosis (IAPs) and Serpins (Thornberry \& Lazebnik 1998, Vercammen et al. 2006). Protease inhibition is utilised as a regulatory step in processes like PCD and plant defence against pathogens and insects (Ryan 1990). There are several kinds of proteases. The largest protease families are serine proteases, aspartate proteases, and cysteine proteases (Beers et al. 2004). Though not much is currently known, it has been shown that proteases can have different substrate specificities (García-Lorenzo 2007). Each protease has a cleavage preference for a specific amino acid and cleaves the peptide bond after this amino acid. For cysteine proteases, a nucleophilic cysteine is first activated by a histidine amino acid via deprotonation and the cysteine nucleophile cleaves the peptide bond of the substrate (Berg et al. 2005, van der Hoorn 2008). An asparagine residue is present in order to orient the histidine side chain in the appropriate direction (García-Lorenzo 2007). Examples of cysteine proteases are papain, an enzyme in papaya fruit, and caspases, enzymes involved in apoptosis in animals

\subsubsection{Caspases and Proteins with Caspase-like activity}

Caspases are cysteine dependent aspartate-specific proteases (Lee 2010). As their name implies, caspases cleave substrates after an aspartate (Asp) amino acid residue. The first caspase was isolated from Caenorhabditis elegans (C. elegans) and since then, fourteen have been discovered in mammals with seven of those playing a role in apoptosis. Caspases are first synthesized as an inactive pro-enzyme, called a zymogen. The caspases undergo autoprocessing (autocleaving) which generates a large (p20) and a small (p10) subunit, which brings about conformational change allowing access of the substrate to the active site for cleavage. 
Plants have several different types of caspase-like activities (reviewed in Bonneau et al. 2008). Plant caspase-like activities are named according to the target substrate (eg. YVADase, DEVDase, VEIDase, and Saspase) (Woltering et al. 2004). It is difficult to determine the full spectrum of caspase-like activities in plants, but it is believed that there are up to eight different activities observed in different plant species (see Bonneau et al. 2008 for a complete list). Caspase-like activities have also been demonstrated in several different locations of the cell, such as the vacuole, cytosol and nucleus. It is also currently unclear whether the caspase-like activities observed in plants are directly involved in PCD (Bonneau et al. 2008) and what role they may play. To date, the identity of the plant cysteine proteases with caspase-like activities has only been solved for the caspase1-like YVADase, which is believed to a large extent to be dependent on the activity of plant vacuolar processing enzymes (VPEs) (Hatsugai et al. 2004). The VPEs are stored in an inactive form in the central lytic vacuole, and are activated after the vacuolar collapse which leads to PCD (Bonneau et al. 2008). No other enzymes responsible for the plant caspase-like activities have been described. Their identity and function(s) in plants remain to be discovered and studied.

\subsubsection{Introduction to Metacaspases}

Following the discovery of caspases in animals, homologous proteases were identified in other organisms. Exhaustive bioinformatic analyses identified two groups structurally similar to caspases, the paracaspases (PCs) and the metacaspases (MCs) (Uren 2000). PCs are present in metazoans, while MCs can be found in plants, bacteria, fungi, chromista, and protozoa (Uren 2000). There are two types of MCs, MC type I and MC type II (Bonneau et al. 2008). MCs type I contain a proline rich prodomain which is structurally similar to the prodomain found in animal caspases involved in PCD initiation and inflammation. MC type I can be found in all lineages between algae to flowering plants, and are also present in protozoa, fungi and chromista as well (Cambra et al. 2010). MC type II, on the other hand, lacks a prodomain but instead contains a longer linker region than that found in type I MCs, which connects the p10 and p20 subunits. MCs type 
II are found only in plants and algae (minus two algae) and not in protozoa, fungi or chromista (Cambra et al. 2010, Uren et al. 2000). The lack of MCs in the two algae is believed to be due to gene loss from environmental adaptation (Cambra et al. 2010). Another difference between the two $\mathrm{MC}$ types is the presence of a $L S D$ 1-like-finger Nterminal motif in MC type I. $L S D I$ has been shown to halt PCD when the hypersensitive response is initiated, and all three MC type I can strongly interact with $L S D 1$. MC type II can only weakly interact with LSDI (Coll et al. 2010). There is no known connection between the gene numbers of MC type I vs. MC type II within different species.

\subsubsection{Similarities and differences between caspases, and MCs}

One common characteristic among caspases and both types of MCs is the presence of a histidine/cystein (His/Cis) dyad (Cambra et al. 2010). Predicted analysis suggests that MCs contain a caspase/hemoglobinase fold consisting of a histidinecysteine pair, and has thus been placed into the CD cystein protease clan (Aravind \& Koonin 2002, Barrett \& Rawlings 2001, Vercammen et al. 2004). This clan contains all enzymes that use a catalytic cysteine to hydrolyse peptide bonds of their substrates (Cambra et al. 2010). MCs also share the $S_{1}$ pocket forming residues and maturation sites seen within the caspase/hemoglobin fold (Sundström et al. 2009). Similar to caspases, MCs also show the presence of a heterodimer made up of the p20 and p10 subunits (Woltering et al. 2002, Vercammen et al. 2004). Studies have shown that MCs along with caspases need to be activated via autoprocessing and that this process is cysteine dependant (Vercammen et al. 2004, Belenghi et al. 2007, Watanabe \& Lam 2011).

Even though caspases and MCs both contain a His/Cis dyad, show a similar secondary structure, and share a basic mechanism of catalysis, there are still defining differences between the two. One of the largest differences between the two protease families is the amino acid after which they cleave (Bonneau et al. 2008). In caspases, cleavage occurs after acidic aspartate, while MCs cleave after either a basic lysine (Lys) or arginine (Arg) residue (Vercammen et al. 2004, Watanabe \& Lam 2005, Watanabe \& Lam 2011). A second major difference is the low sequence homology between the two 
protease families (Cambra et al. 2010). The overall similarity of the two sequences is not high (Belenghi et al. 2007, Cambra et al. 2010), and while MCs have two cysteine residues in their sequence, caspases only have one (Belenghi et al. 2007). Due to these differences, it is considered unlikely that MCs are indeed homologs to caspases (Vercammen et al. 2004, Bonneau et al. 2008). Despite the fact that MCs have similar morphology and secondary structure as caspases, since MCs do not show cleavage specificity for Asp, they can not be defined as a caspase (Woltering et al. 2002).

\subsection{Analysis of MC Functions}

\subsubsection{Enzyme activity and substrate/inhibitor analyses}

There are a total of nine Arabidopsis MC genes making up a gene family (Figure 1.1) which consists of three MC type I (AtMC1-3) and six MC type II genes (AtMC4-9). AtMC mutants do not show obvious phenotypic differences, most likely due to significant functional redundancy (Bonneau et al. 2008). Overexpression of MC genes in transgenic plants have been equally uninformative of their function (Bonneau et al. 2008), likely due to post translational modifications by the serpin enzymes (Vercammen et al. 2006), or because overexpression is merely not creating any visible phenotype.

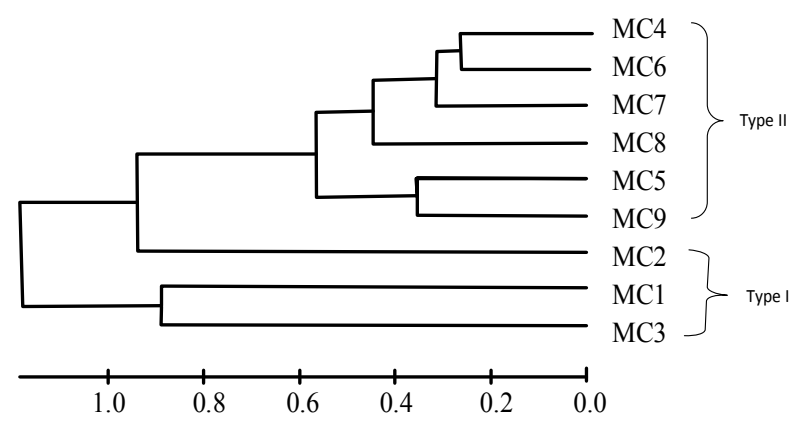

Figure 1.1: AtMC phylogenetic tree. Relationship between protein sequences of the nine $\mathrm{MC}$

Arabidopsis genes (created by Mega5). 
Up until recently, there were no known substrates for MCs. It has been shown that the human Tudor staphylococcal nuclease (TSN) is a substrate for animal caspases (Sundström et al. 2009). Discovery of conserved plant TSN suggested this may be a substrate for MC cleavage. A recent study in Picea abies (P. Abies) and Arabidopsis has shown that in both plants, TSN was cleaved by MCs at Lys or Arg in vivo (Sundström et al. 2009).

In support of the initial discovery that MCs cleave after Arg and Lys, two purified Arabidopsis MCs (AtMC4 and AtMC9) were tested using five oligopeptide substrates containing an Arg or a Lys. All five substrates were cleaved by both MCs at the predicted amino acids, while neither of the two MCs was capable of cleaving three chosen caspasespecific oligopeptide substrates containing Asp (Vercammen et al. 2004). The same MC cleavage specificity was observed in $P$. abies, as well. A fluorometric peptide cleavage assay of Escherichia coli (E. coli) expressed recombinant mcII-Pa (spruce MC) zymogen showed cleavage after both Arg and Lys, separating the p20 and p10 subunits from the linker region (Bozhkov et al. 2005). There was no cleavage when caspase-specific substrates were added to recombinant mcII-Pa.

To further test the functional homology between caspases and MCs, the effects of protease inhibitors which normally affect caspases were tested on AtMC4 and AtMC9 (Vercammen et al. 2004). These inhibitors were unable to block either MC from binding to their synthetic substrate at very high concentrations (up to $100 \mu \mathrm{M}$ ). However, addition of arginal protease inhibitors instead of caspase inhibitors at concentrations as low as $1 \mu \mathrm{M}$ fully prevented AtMC9 from cleaving its substrate, while AtMC4 was moderately blocked (Vercammen et al. 2004). After determining that AtMC4 and AtMC9 were Arg/Lys specific, Vercammen et al. 2006 went one step further and used an Arabidopsis Serpin1 inhibitor (AtSerpin1) identified in a yeast two-hybrid system to test AtMC9 substrate specify and discovered that this plant protease inhibitor did indeed inhibit activity of AtMC9. 
It was previously believed that $\mathrm{MC}$ proteins may be localized in the cytoplasm of plant cells due to their lack of a signal peptide (Woltering et al. 2004). Several studies showed that different AtMCs have different $\mathrm{pH}$ optimums. AtMC9 requires a low $\mathrm{pH}$ (between 4.5-6.0) while AtMC4 requires high $\mathrm{pH}$ (between 6.5-9) for activation (Vercammen et al. 2004). Activation of AtMC8 has been shown to occur at the slightly basic $\mathrm{pH}$ of 7.5-8.5 (He et al. 2007). This leads to the speculation that if different AtMCs do localize to the cytoplasm, yet require different $\mathrm{pH}$ environments, the function of these MCs must be correlated with events triggering significant ion exchanges which can significantly change the $\mathrm{pH}$ of the cytosol. Studies in tobacco show that the elicitor cryptogein induces acidification of the cytosol, while $\mathrm{NaCl}$ can significantly lower the $\mathrm{pH}$ in less than an hour (Vercammen et al. 2004). It seems likely that AtMCs will have different activation conditions depending on their localization, their signalling pathways and their overall role in plant development.

Another study has suggested that AtMC9 localization takes place in the apoplast. Due to the low $\mathrm{pH}$ required for activation of this AtMC, apoplastic localization is logical (Vercammen et al. 2006). It is also possible that AtMC proteins localize in either the nucleus or the vacuole. When $A t M C 9$ under a $35 \mathrm{~S}$ promoter was fused to GFP, a strong GFP signal was observed in the nucleus and a weaker signal in the cytosol. No signal was observed in the vacuole, but this could be attributed to masking of the vacuolar signal sequence by the reporter gene fusion (Vercammen et al. 2004). A study using 35S::AtMC1::GFP fusion showed that AtMC1 localizes in the chloroplasts (CastilloOlamendi et al. 2007). To date, no systematic study of all AtMCs' localization has been performed.

The identification of AtSerpin1 as an inhibitor of AtMC9 may suggest a possible regulatory role for AtSerpin1 in Arabidopsis MCs' regulation. In addition to AtSerpin1, autoprocessing and S-nitrosylation have also been suggested to play an active role in the control of MCs at both the transcriptional and post-transcriptional levels. Studies on AtMC9 have shown that enzyme activity is conditional on cleavage at Arg183 
(Vercammen et al. 2004). It is currently unknown what triggers autoproccessing in MCs but possibilities include initiation by a change in $\mathrm{pH}$, by other proteases, by metacaspases themselves, or by the addition of Calcium $\left(\mathrm{Ca}^{2+}\right)$. According to Vercammen et al. in 2004 in Arabidopsis type II MCs overproduction of all AtMCs in bacteria lead to autoproccessing similar to the way some caspases initiate cleavage. Caspases are capable of cleaving themselves and are broken down into two groups, initiator caspases, and effector caspases. Initiator caspases are auto-activated and are required for activation of effector caspases, (Riedl \& Shi 2004). Also shown in this publication was the fact that AtMC9 requires an acidic $\mathrm{pH}$ for activation. A recent study has determined that in some AtMCs $\mathrm{Ca}^{2+}$ is necessary for conversion of the proenzyme into the catalytically active form by promoting cleavage of the highly conserved Lys-225 residue found in all type II MCs. This $\mathrm{Ca}^{2+}$ dependency was observed in AtMC4, but not in AtMC9, suggesting that not all $\mathrm{MC}$ type II proteases require $\mathrm{Ca}^{2+}$ for activation of the zymogen and thus may have a different function and activation mechanism (Watanabe \& Lam 2011).

Another process thought to regulate $\mathrm{MC}$ activity is S-nitrosylation. This occurs when the active Cys residue in MCs is nitrosylated in the presence of nitric oxide (NO). Nitric oxide is a signalling molecule that exists in both the intracellular and intercellular regions of plants and is transported via the plant xylem (Ohashi-Ito et al. 2010). When a NO is covalently attached to a cysteine, the protein undergoes post translational modification (Belenghi et al. 2007). S-nitrosylation and its link to enzyme inhibition was first described in animal procaspase 3. MCs can also be regulated by S-nitrosylation. It has been shown that Cys-147 S-nitrosylation impedes AtMC9 autoprocessing (Belenghi et al. 2007). Cys-29 in the same protein, however, is immune to S-nitrosylation and is able to restore the autoprocessing function of the metacaspase (Belenghi et al. 2007).

\subsubsection{Developmental Functional characterisation}

Saccharomyces cerevisiae (S. cerevisiae) (baker's yeast) was the first organism used to study MCs and their relationship with PCD. The single S. cerevisiae metacaspase, yeast caspase 1 (Ycal) is required for hydrogen peroxide induced aging and apoptosis, 
while overproduction of $Y c a l$ results in early aging (Madeo et al. 2002). A recent study has shown that $Y c a l$ also plays a role in the control of aggregate formation of insoluble proteins by controlling their removal (Lee et al. 2010). P. abies somatic embryos have been a valuable system in understanding the role of a MC in embryogenesis in general (Helmerssoon 2007). RNAi down-regulation of a P. abies type II metacaspase ( $m c I I-P a)$ led to a decrease in PCD of the embryo suspensor cells (Suarez et al. 2004). Further studies have shown that mcII-Pa moves from the cytoplasm to the nuclei of undifferentiated embryonic cells, leading to DNA fragmentation, and disassembly of the nuclear envelope resulting in PCD of those cells. After silencing $m c I I-P a$, the cells no longer disintegrated suggesting that MCs do play in role in plant PCD (Bozhkov et al. 2005). It has also been shown that Arabidopsis MC8 is upregulated by $\mathrm{H}_{2} \mathrm{O}_{2}$ and other types of stresses. In the AtMC8 loss-of-function mutant, cell death was reduced after $\mathrm{H}_{2} \mathrm{O}_{2}$ treatment suggesting that $A t M C 8$ is induced and controls a response to oxidative stress through promoting PCD (He et al. 2007).

It has also been shown that PCD can be activated in response to pathogens. Plants with insertional disruptions in two AtMC type I, and five AtMC type II genes were inoculated with Botrytis cinerea, a necrotrophic fungi known to affect a range of different plants. After infection, all seven MC mutants showed a significant reduction in cell death over the Wild-type (van Baarlen et al. 2007). Other studies have suggested differential roles for the two types of MCs in response to bacterial pathogens. Two of the type I Arabidopsis MCs (AtMCl and AtMC3) were upregulated by various bacterial pathogens, while none of the type II MCs showed any induction (He et al. 2007). A different study concluded that all three type I MCs and two type II MCs (MC5 and MC8) were activated upon infection with various bacterial pathogens (Watanabe \& Lam 2005). 


\subsection{My Thesis: The value in determining the function of MC genes and their connection to programmed cell death in Arabidopsis thaliana}

\subsubsection{Value of the project}

Manipulation of tree biomass is of substantial interest to timber, bioenergy and pulp/paper industries. Trees provide long-term carbon storage with mitigates the negative effects of $\mathrm{CO}_{2}$ emissions and associated climate changes. The main biomass of trees resides in the woody tissues of the stem, which is the secondary xylem of the trees. Xylem plays a role in water and nutrient transport as well as providing mechanical strength. It contains three different cell types, parenchyma cells, fibers and treachery elements (TE) (Ohashi-Ito 2010). Parenchyma cells are alive and are only a relatively minor part of xylem total biomass. Fibers are highly lignified and provide mechanical support to the tree. Treachery elements can be either tracheids or vessel elements (VEs). One venue to increase biomass is to manipulate genes responsible for PCD in the tree xylem. Postponing PCD would lead to the development of thicker cell walls in xylem, thus leading to increased biomass.

In order to fully understand, and to be able to manipulate PCD in plants, the players involved in the process of PCD should first be discovered. PCD is a highly organized process and thus the mechanism and interaction between the different players should be subsequently well-understood. This thesis focused only on the first step, identification of the key players. The objective of the thesis was to determine if the distantly related $\mathrm{MC}$ genes play a role in plant PCD similar to the way caspases play a role in animal PCD. The long term goal of this project is to prolong the lifetime of xylem fibers through modification of genes involved in PCD to create thicker cell walls leading to higher wood density, and thus higher biomass.

\subsubsection{Why study MCs?}

The primary interest in MCs is in relation to their putative role(s) in PCD in plants. Although the role of MCs in PCD is yet unclear (He et al. 2008, Cambra et al. 2010) they are the closest known homologs to caspases in animals and thus good putative 
targets that can provide an entry point to our understanding of PCD in plants. In addition to playing a direct role in PCD, MCs may also be indirectly involved in PCD via a signalling pathway(s) which ultimately leads to cell death (Bonneau et al. 2008). For example, the deactivation or activation of other proteins could be necessary for PCD, and proteases such as metacaspases could be speeding up the reaction (Bonneau et al. 2008). It is also probable that since MCs comprise a large gene family, some of them may play a more direct role in PCD than others. PCD is not the only known function for caspases, they have been implicated in activation of the immune system and differentiation of different cell types (Lee et al. 2010). This suggests that MCs may have other functions in plant growth and development which are not even speculated. Thus the function of MCs in relation to PCD, and in general, is still a mystery (Cambra et al. 2010). Thus, study of MCs may provide new fundamental insights into plant development and provide useful means for manipulation of woody biomass.

\subsubsection{Objectives and goals of the thesis}

Due to the many experimental advantages, we choose Arabidopsis for the analysis of MCs' roles in plant PCD. Though it is not a tree species, it can produce secondary woody-like xylem in the hypocotyl and thus can be used as proxy for studies of wood development. Of the nine MC genes in Arabidopsis, the most heavily analyzed has been AtMC9, and yet, information regarding even AtMC9 is minimal. Some work has been done on AtMC4 and AtMC8, but there is relatively nothing known about the other AtMC genes, other than their structure and the fact that they do indeed fall into the MC category. Therefore, this work focused on a broader and more general characterization of the whole AtMC gene family, however, particular focus was placed on AtMC 9 because of its putative importance for wood development. Previous expression data from poplar suggests that a putative aspen ortholog of AtMC 9 is expressed during the stage of PCD of xylem development. 
There were three main objectives of this thesis.

- To analyze the expression pattern of the Arabidopsis metacaspase genes using the rich expression databases for this species in order to understand the expression pattern of the different genes across different developmental stages and in response to stress and other stimuli.

- Generate and preliminarily analyze transgenic lines expressing translational beta-glucuronidase GUS fusions of each AtMC gene. The goal was to produce AtMCpromoter::AtMCgene::GUS lines for each of the AtMCs in Arabidopsis. This study would point to organ/tissue specific level localization of each MC genes' activity.

- To study the developmental function of the different members of the Arabidopsis metacaspase gene family. This was performed using reverse genetics on both single mutants from each of the gene family members, and on double mutants created by crossing each of the single mutants with the AtMC9 mutant.

The hypothesis was that AtMC genes do play a direct role in PCD. 


\section{Materials and methods}

\section{$2.1 \quad$ Plant Material}

Arabidopsis thaliana (A. thaliana) ecotype 'Columbia' (Col-O) were used as Wild-type controls. Arabidopsis MC homozygous T-DNA insertion mutants were obtained from the Syngenta Arabidopsis Insertion Library (SAIL), the Salk Institute for Biological Studies (SALK), and from the GK project (GABI-KAT). See Table 2.2 for a complete list of single and double mutants analyzed.

\subsection{Growth Conditions}

Plants were grown in a controlled growth chamber at $22^{\circ} \mathrm{C}$ during the day and $19^{\circ} \mathrm{C}$ at night. Light conditions were typical long days with 16 hours of light and 8 hours of dark with a PAR of $150 \mu \mathrm{mol} / \mathrm{m}^{-2} / \mathrm{s}^{-1}$. More information can be found at http://www.upsc.se/ under "Resources-Controlled environment."

\subsection{DNA Extraction}

Genomic DNA for PCR was extracted from $A$. thaliana leaves using extraction buffer (See section 2.12), heated and centrifuged to produce a supernatant, precipitated with equal volume of isopropanol, washed with $70 \%$ ethanol dried at room temperature and resuspended in $50 \mu 1$ Tris. DNA was analyzed using a Nanodrop spectrophotometer.

\section{$2.4 \quad$ Gene expression studies}

We studied the expression of the 9 AtMCs using Genevestigator (https://www.genevestigator.com/gv/index.jsp). This meta-profile analysis tool was used to collect expression data on the tissues, developmental stages, and stimulus treatments for the 9 Arabidopsis MCs. The data in Genevestigator was compiled from a large collection of Affymetrix microarrays. 


\subsection{GUS histochemical staining}

Leaves were incubated at $37^{\circ} \mathrm{C}$ for $24 \mathrm{~h}$ in $1 \mathrm{mM} \mathrm{K}_{4} \mathrm{Fe}(\mathrm{CN})_{6}, 1 \mathrm{mM} \mathrm{K}_{3} \mathrm{Fe}(\mathrm{CN})_{6}$, $50 \mathrm{mM}$ sodium phosphate buffer $(\mathrm{pH} 7)$ and $0,1 \%$ Triton X-100. After incubation, samples were destained in $70 \% \mathrm{EtOH}$, mounted in $50 \%$ glycerol and viewed with a Zeiss Axioplan light microscope.

\subsection{Genotyping}

Prior to genotyping, seeds from $m c 9-1 m c 4$ and $m c 9-2 m c 4$ double mutants were grown on regular MS media and were selected for reduced growth. $m c 9-1 m c 5$ double mutant seeds were plated on antibiotic medium and selected for survival. mc6 mutant seeds were sown directly into soil. DNA from these mutants was extracted from young leaf tissues as described above. A list of primer sequences can be found in Table 2.1.

Table 2.1

Primers used for genotyping. Genomic $\mathrm{Col}-\mathrm{O}$ was used as negative control

\begin{tabular}{|l|l|}
\hline GK forward & CCTTTTTCCTTTTAGAGTACACCAC \\
\hline GK reverse & TTCGGATTCAAACAAGACGAC \\
\hline GK LB & GGGCTACACTGAATTGGTAGCTC \\
\hline Sail 856D05 forward & AACTTCTTCACTTTCGGGCTC \\
\hline Sail 856D05 reverse & AATGTCTCGTTGAACGGTACG \\
\hline Sail 856D05 LB1 & GCCTTTTCAGAAATGGATAAATAGCCTTGCTTCC \\
\hline Salk LB1.3 & ATTTTGCCGATTTCGGAAC \\
\hline Salk 006679 forward & AAACCGAGCATTGACATAAGC \\
\hline Salk 006679 reverse & CCATTACAGTGGACATGGGAC \\
\hline Salk 145461 forward & ACACATGTTGGGAACAAGCA \\
\hline
\end{tabular}




\subsection{Phenotyping}

\subsubsection{Mutants and experimental design}

Single mutations for all genes, with the exception of AtMC5 and AtMC8, for which there were no mutants available, were crossed into the $m c 9-1$ or $m c 9-2$ mutants' background. Plants from Table 2.2 were sown directly into soil. Trays were rotated around the growth chamber once a week.

Table 2.2

AtMC single and double mutants analyzed in the phenotype screening. Asterisk (*) indicate genes for which mutants were unavailable for pheontyping

\begin{tabular}{|c|c|c|c|c|c|}
\hline $\begin{array}{l}\text { Single Mutant } \\
\text { T-DNA } \\
\text { insertion line }\end{array}$ & $\begin{array}{l}\text { AtMC } \\
\text { gene }\end{array}$ & $\begin{array}{l}\text { TAIR } \\
\text { Accession } \\
\text { Number }\end{array}$ & $\begin{array}{l}\text { AtMC gene } \\
\text { number } \\
\text { abbreviation }\end{array}$ & Double Mutant T-DNA insertion line & $\begin{array}{l}\text { AtMC gene } \\
\text { number } \\
\text { abbreviation }\end{array}$ \\
\hline $\begin{array}{l}\text { Col Wild-type } \\
\text { (Control) }\end{array}$ & & & & & \\
\hline $\begin{array}{l}\text { SALK075814 } \\
\text { (Salk 14) }\end{array}$ & MC9 & At5g04200 & $m c 9-2$ & & \\
\hline $\begin{array}{l}\text { GABI } 540 H 06 \\
(G K)\end{array}$ & $M C 9$ & At5g04200 & $m c 9-1$ & & \\
\hline GABI 096A10 & $M C 1$ & At1g02170 & $m c 1-1$ & GABI 540H06 x GABI 096A10 & $m c 9-1 m c 1-1$ \\
\hline SALK 002986 & $M C 1$ & At1g02170 & $m c 1-2$ & GABI 540H06 x SALK 002986 & $m c 9-1 m c 1-2$ \\
\hline SALK 009045 & $M C 2$ & At4g25110 & $m c 2$ & GABI 540H06 x SALK 009045 & $m c-9-1 m c 2$ \\
\hline GABI 545D06 & $M C 3$ & At5g64240 & $m c 3$ & GABI 540H06 x GK 545D06 & $m c 9-1 m c 3$ \\
\hline SAIL 856D05 & $M C 4$ & Atlg79340 & $m c 4$ & SALK14xSAIL856D05 & $m c 9-2 m c 4$ \\
\hline $\begin{array}{l}\text { SALK } \\
145461 C^{*}\end{array}$ & $M C 5^{*}$ & At1g79330 & $m c 5$ & GABI 540H06 x Salk 145461* & $m c 9-1 m c 5^{*}$ \\
\hline SALK 063453 & MC6 & At1g79320 & $m c 6-1$ & GABI 540H06 x SALK 063453 & $m c 9-1 m c 6-1$ \\
\hline SALK 006679 & MC6 & At1g79320 & $m c 6-2$ & GABI 540H06 x Salk 006679 & $m c 9-1 m c 6-2$ \\
\hline \multirow[t]{2}{*}{ SALK 127688} & $M C 7$ & At1g79310 & $m c 7$ & GABI 540H06 x SALK 127688 & $m c 9-1 m c 7$ \\
\hline & $M C 8^{*}$ & At1g16420 & $m c 8$ & & \\
\hline
\end{tabular}




\subsubsection{Phenotyping Data Collection}

Data collection on rosette development and stem height was separated into three different experiments. Experiment one contained $m c 9-2 m c 4$ mutants, the second consisted of $m c 6-2$ mutants and the third analyzed the remaining mutants with the exception of $m c 5$ and $m c 8$. The number of leaves, minus the cotyledons, per plant was counted after three weeks of growth under long days. During week six, data on the number of leaves per rosette, the width of the broadest leaf per rosette, and the size of each rosette was collected. Leaf width was determined by measuring the distance across the widest leaf per mutant per line. Rosette size was determined by measuring the length from the tip of the longest leaf to the tip of the leaf directly horizontal to it. The largest distance per mutant plant per line was recorded. Senescence occurred until week seven and individual plant senescence was analyzed by recording the number of leaves showing yellowing and dividing that number by the total number of leaves on the plant. During week seven the stem of each plant was measured from the base of the rosette to the tip of the main stem. Photographs of each phenotypic characteristic during week six were taken using a Canon EOS 450D. For bolting time, data was not collected from $m c 9-2 m c 4$ or $m c 6$ and thus one control was used. The percentage of plants in each line showing the presence of bolting during weeks 3-5 were recorded. After week seven, nine out of the ten plants were dissected and the hypocotyls were removed and fixed in FAA (see section 2.12). The remaining plant was grown to full maturity and seeds were harvested.

\subsubsection{Data analysis}

Excel was used to record, analyze and graph data. In order to combine data from three different experiments each trait in the mutants was calculated as a proportion from the Wild-type in its own particular experiment. Statistical significant differences were determined using a two independent sample two-tailed t-test with 18 degrees of freedom. Lines were considered to be significantly different from the Wild-type control if the pvalue was less than or equal to 0.05 . 


\subsection{Production of Promoter::gene:::GUS constructs}

\subsubsection{Primer design and PCR of AtMC1-9:}

The Arabidopsis Information Resource (TAIR) database was used to locate the sequences of AtMC1-9 genes. Primers were designed for the promoter::gene construct using Vector NTI 11 (Invitrogen). The promoter was cloned in order to incorporate the endogenous promoter into the construct while the genes themselves were included in the construct in order to insure that any transcription machinery coded for within the gene would be included along with post-transcriptional regulatory sequences. In the reverse primers, a cytosine was added immediately after the last nucleotide of the attB sequence in order to maintain the proper reading frame. Inset primers (p800) were designed as needed to cover gap regions during sequencing (Table 2.3). Phusion ${ }^{\circledR}$ polymerase (Finnzymes) was to amplify the different gene fragments during PCR.

\section{Table 2.3}

Forward, reverse and inset primer sequences for cloning in the 5' $-3^{\prime}$ ' direction.

The additional cytosine is underlined.

\begin{tabular}{|l|l|l|c|}
\hline Gene & \multicolumn{1}{|c|}{ Primer Sequence } & Inset Primer Sequence (p800) & $\begin{array}{l}\text { Fragment } \\
\text { Size (kb) }\end{array}$ \\
\hline $\begin{array}{l}\text { At1g02170- } \\
\text { MC1F }\end{array}$ & $\begin{array}{l}\text { GGGGACAAGTTTGTACAAAAAAGCAGG } \\
\text { CTTACCAATGATGTCTCAGAAC }\end{array}$ & TCAACGACGCCAAGTGCATGC & 2.0 \\
\hline $\begin{array}{l}\text { At1g02170- } \\
\text { MC1R }\end{array}$ & $\begin{array}{l}\text { GGGGACCACTTTGTACAAGAAAGCTGGG } \\
\text { TACGAGAGTGAAAGGCTTTGC }\end{array}$ & CGGCGAGCCCTTTTCCTT & \\
\hline $\begin{array}{l}\text { At4g25110- } \\
\text { MC2F }\end{array}$ & $\begin{array}{l}\text { GGGGACAAGTTTGTACAAAAAAGCAGG } \\
\text { CTTACTTCCCCCTTGATCTTCGTCG }\end{array}$ & GCGCTCCCTGACAATTGC & 2.9 \\
\hline $\begin{array}{l}\text { At4g25110- } \\
\text { MC2R }\end{array}$ & $\begin{array}{l}\text { GGGGACCACTTTGTACAAGAAAGCTGGG } \\
\text { TACTAAAGAGAAGGGCTTCTCATATA }\end{array}$ & TTCATGGGTTTCAACAGC & \\
\hline $\begin{array}{l}\text { At5g64240- } \\
\text { MC3F }\end{array}$ & $\begin{array}{l}\text { GGGGACAAGTTTGTACAAAAAAGCAGG } \\
\text { CTTAAGATACGCAACAGAGTTC }\end{array}$ & TTCTTGTCGTTCATTACA & 2.0 \\
\hline $\begin{array}{l}\text { At5g64240- } \\
\text { MC3R }\end{array}$ & $\begin{array}{l}\text { GGGGACCACTTTGTACAAGAAAGCTGGG } \\
\text { TACGAGTACAAACTTTGTCGCG }\end{array}$ & ATCATCACCAAACGCATCAA & \\
\hline $\begin{array}{l}\text { At5g64240- } \\
\text { MC3R }\end{array}$ & $\begin{array}{l}\text { GGGGACCACTTTGTACAAGAAAGCTGGG } \\
\text { TACGAGTACAAACTTTGTCGCG }\end{array}$ & & \\
\hline
\end{tabular}


Table 2.3 continued

\begin{tabular}{|c|c|c|c|}
\hline Gene & Primer Sequence & Inset Primer Sequence (p800) & $\begin{array}{l}\text { Fragment } \\
\text { Size (kb) }\end{array}$ \\
\hline $\begin{array}{l}\text { Atlg79340- } \\
\text { MC4F }\end{array}$ & $\begin{array}{l}\text { GGGGACAAGTTTGTACAAAAAAGCAGGCT } \\
\text { TAAGGAAATTTAAATTTAGATCCGGTT }\end{array}$ & GGGATGCGTCAACGATGT & 2.1 \\
\hline $\begin{array}{l}\text { At1g79340- } \\
\text { MC4R }\end{array}$ & $\begin{array}{l}\text { GGGGACCACTTTGTACAAGAAAGCTGGGT } \\
\text { ACACAGATGAAAGGAGCGTT }\end{array}$ & & \\
\hline $\begin{array}{l}\text { At1g79330- } \\
\text { MC5F }\end{array}$ & $\begin{array}{l}\text { GGGGACAAGTTTGTACAAAAAAGCAGGCT } \\
\text { TATTCATATCCCAAGTACTG }\end{array}$ & GCTCTCTCCGATCTGCTCTT & 2.1 \\
\hline $\begin{array}{l}\text { At1g79330- } \\
\text { MC5R }\end{array}$ & $\begin{array}{l}\text { GGGGACCACTTTGTACAAGAAAGCTGGGT } \\
\text { ACACAAATAAACGGAGCATT }\end{array}$ & & \\
\hline $\begin{array}{l}\text { At1g79320- } \\
\text { MC6F }\end{array}$ & $\begin{array}{l}\text { GGGGACAAGTTTGTACAAAAAAGCAGGCT } \\
\text { TATTTGACTATTTCTTATAAGC }\end{array}$ & ATACTGGTTACGATGAGT & 1.7 \\
\hline $\begin{array}{l}\text { At1g79320- } \\
\text { MC6R }\end{array}$ & $\begin{array}{l}\text { GGGGACCACTTTGTACAAGAAAGCTGGGT } \\
\text { ACACATATAAACCGAGCATT }\end{array}$ & & \\
\hline $\begin{array}{l}\text { At1g79310- } \\
\text { MC7F }\end{array}$ & $\begin{array}{l}\text { GGGGACAAGTTTGTACAAAAAAGCAGGCT } \\
\text { TAATCTTACCTTACGGTACA }\end{array}$ & AATGTTTAGTATTTTAAT & 2.3 \\
\hline $\begin{array}{l}\text { At1g79310- } \\
\text { MC7R }\end{array}$ & $\begin{array}{l}\text { GGGGACCACTTTGTACAAGAAAGCTGGGT } \\
\text { ACGCATATAAACGGAGCATT }\end{array}$ & & \\
\hline $\begin{array}{l}\text { Atlg16420- } \\
\text { MC8F }\end{array}$ & $\begin{array}{l}\text { GGGGACAAGTTTGTACAAAAAAGCAGGCT } \\
\text { TATATGGAGGCTTTAGTGGTACAG }\end{array}$ & AAAGCACTTTTGATAGGAATCA & 2.3 \\
\hline $\begin{array}{l}\text { At1g16420- } \\
\text { MC8R }\end{array}$ & $\begin{array}{l}\text { GGGGACCACTTTGTACAAGAAAGCTGGGT } \\
\text { ACGTAGCATATAAATGGTTT }\end{array}$ & & \\
\hline $\begin{array}{l}\text { At5g04200- } \\
\text { MC9F }\end{array}$ & $\begin{array}{l}\text { GGGGACAAGTTTGTACAAAAAAGCAGGCT } \\
\text { TACATAAATGGTTCGTCTCA }\end{array}$ & TGAAGACGTTTAATTTCTG & 1.6 \\
\hline $\begin{array}{l}\text { At5g04200- } \\
\text { MC9R }\end{array}$ & $\begin{array}{l}\text { GGGGACCACTTTGTACAAGAAAGCTGGGT } \\
\text { ACEAGGTTGAGAAAGGAACGT }\end{array}$ & & \\
\hline
\end{tabular}

\subsubsection{Production of constructs using Gateway ${ }^{\circledR}$ cloning}

The promoter::gene::GUS constructs were created using the Gateway®

manufacturer's instructions. A BP reaction inserted the amplified fragments into the entry clone, pDONOR207, and the LR reaction inserted it into the expression binary vector, pKGWFS7.0. A colony PCR was used to confirm the presence of the entry clone. DNA was isolated using a miniprep and the concentration was measured. Plasmid DNA was 
sequence validated and transformed into Agrobacteria after the LR reaction as described below.

\subsubsection{Transformation of $\boldsymbol{E}$. coli and Agrobacterium}

Electrocompetent E. coli strain DH5a cells and Agrobacterium strain GV3101::pMP90RK were transformed using electroporation via a BioRad Gene Pulser. E.coli cells were incubated at $37^{\circ} \mathrm{C}$ on a shaker for 1 hour while Agrobacterium was incubated at $28^{\circ} \mathrm{C}$ for 48 hours. After PCR validation, the starter culture was incubated on a shaker for 24 hours at $28^{\circ} \mathrm{C}$. A. thaliana Col-O with newly opened flowers were dipped into the respective Agrobacterium solution. Three plants per construct were used. Plants matured for 4 weeks until harvesting.

\subsection{Sequencing}

Plasmid DNA from Entry clones (50-100ng) was sent to Eurofins MWG Operon for sequencing DNA. L1 and L2 primers were provided by Eurofins and p800 inset primers were added to the samples prior to sending in order to cover the middle region of the sequence.

\subsection{Sequence Analysis}

Each MC nucleotide sequence from the sequencing result was aligned to the original MC nucleotide sequence from Vector NTI using MultAlign (http://multalin.toulouse.inra.fr/multalin/multalin.html). Nucleotide sequences of AtMCs from TAIR were converted to protein sequences using the European Molecular Biology EBI: Transequence Nucleotide to Protein Sequence Conversion (http://www.ebi.ac.uk/Tools/emboss/transeq/index.html) and a phylogenetic tree was produced using Molecular Evolutionary Genetics Analysis (Mega5) software. 


\subsection{T-DNA insertion sites}

T-DNA insertion sites for all AtMC genes were located using

http://signal.salk.edu/cgi-bin/tdnaexpress. The relative location inside the gene between the start and stop codons were determined using http://arabidopsis.org/ (Figure 2.1).

MC1 (At1g392654-432654)

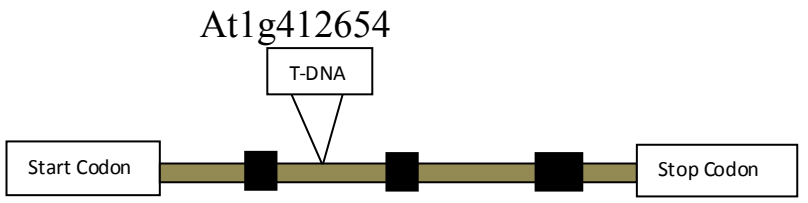

MC2 (At4g12868845-12908845)

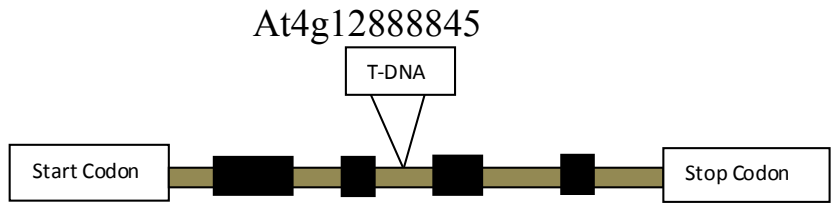

MC3 (At5g25676379-25716379)

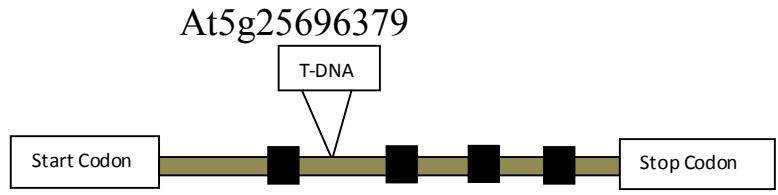

MC4 (At1g29823608-29863608)

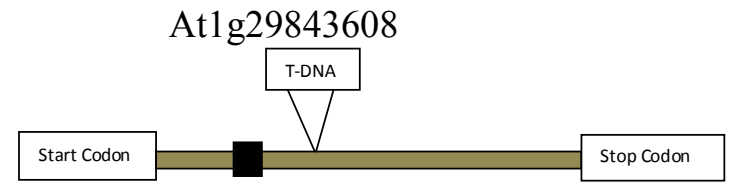

MC5 (At1g29819429-29859429)

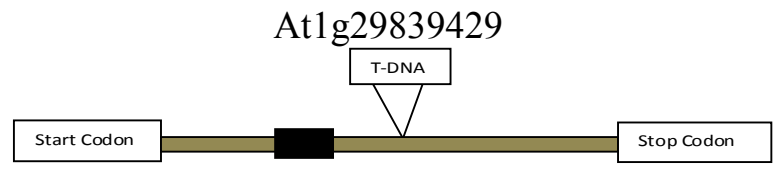


MC6 (At1g29817297-29857297)

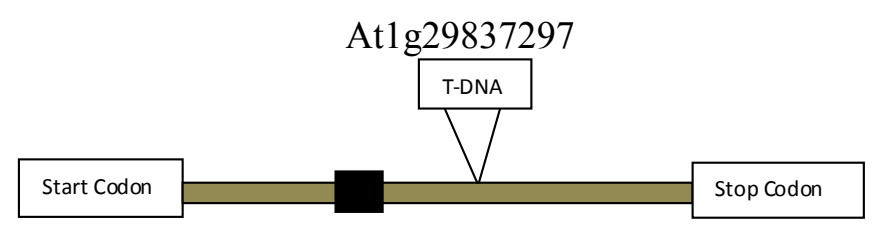

MC7 (At1g29814699-29854699)

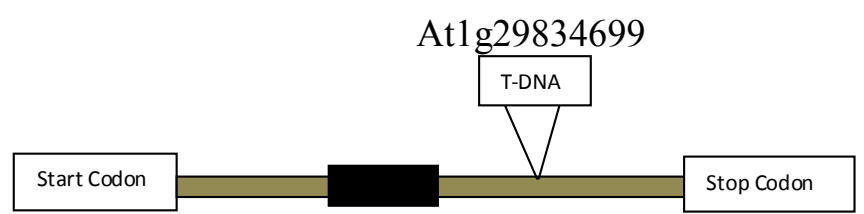

MC8 (At1g5593066-5633066)

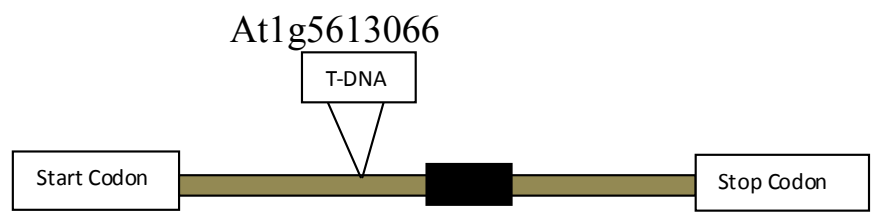

MC9 (At5g1134381-1174381)

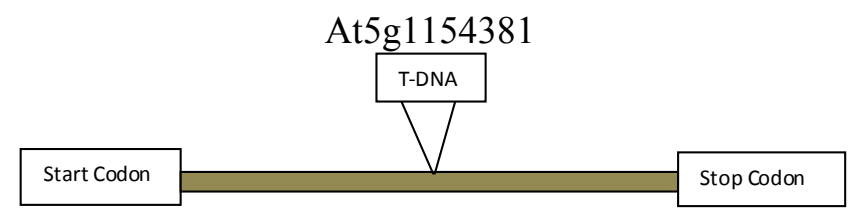

Figure 2.1: Schematic representation of the DNA insertion sites for all AtMCs. The size of the gene is noted along with the location on the chromosome where the TDNA was inserted. Start and stop codons are depicted at the beginning and endings of each gene. Information was obtained from http://signal.salk.edu/cgi-bin/tdnaexpress. 
2.12 Supplemental Material and Methods

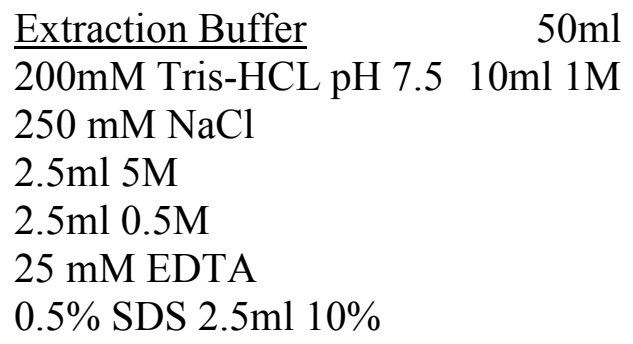

Plate medium-Plants (pH5.8)

4.4g/L MS media

$2.56 \mathrm{ml} / \mathrm{L}$ MES

$10 \mathrm{~g} / \mathrm{L}$ sucrose

$10 \mathrm{~g} / \mathrm{L}$ plant agar

$1 / 1000$ antibiotic

$\underline{\text { PCR reactions-Genotyping }}$

$95^{\circ} \mathrm{C} 1 \mathrm{~min}$.

$95^{\circ} \mathrm{C} 30 \mathrm{sec}$.

$50^{\circ} \mathrm{C} 20 \mathrm{sec}$.

$72^{\circ} \mathrm{C} 3$ min.

$72^{\circ} \mathrm{C} 10$ mins.

$8^{0} \mathrm{C}$ forever

35 cycles
Formalin-Acetic-Alcohol (FAA) $50 \% \mathrm{EtOH}$

$10 \%$ formaldyhyde

$5 \%$ acetic acid

Plate medium-Bacteria $(\mathrm{pH} 7.2)$

1x Luria-Bertani Buljong

15g/l Bacto-Agar

$1 / 1000$ antibiotic

PCR reactions-Cloning

$95^{\circ} \mathrm{C} 1 \mathrm{~min}$

$95^{\circ} \mathrm{C} 20 \mathrm{sec}$.

$44-61{ }^{\circ} \mathrm{C} 20 \mathrm{sec}$

$72^{\circ} \mathrm{C} 3 \mathrm{~min}$

$72^{\circ} \mathrm{C} 10 \mathrm{~min}$

$4^{0} \mathrm{C}$ forever

35 cycles 


\section{Results}

\subsection{Isolation and validation of $A t M C$ mutants}

Previously, the effect of each T-DNA insertion on gene expression was analyzed for reduction or complete absence of expression (Table 3.1). All mutant lines were previously genotyped to confirm homozygous mutations, except for $m c 9-1 m c 5$ which, after genotyping, showed no conclusive data for the presence of a double homozygous mutation.

\subsection{In silico expression analysis of the $A t M C$ gene family}

With the exception of AtMC4 which showed consistent and relatively similar expression in all developmental stages, each $A t M C$ showed a noticeable peak in different developmental stages, in different tissues, and in response to inductive stimuli (Table 3.2). High expression values were determined for AtMCl-4 and 9, with AtMC4 having the highest expression levels in all developmental stages. Expression for all AtMCs was detected during all stages analyzed. AtMC9 was highly expressed in root xylem, while AtMC1-4 showed higher expression values than AtMC5-8 across all of the tissues studied. $A t M C 7$ was not expressed in young leaf tissue (Figure 3.1). During response to inductive treatment, AtMC5-8 showed higher expression while AtMC1-4 and AtMC9 consistently displayed minimal expression. Neither $A t M C 7$ nor $A t M C 9$ were expressed in response to heat treatment (Table 3.2, Figure 3.1). 


\section{Table 3.1}

RT-PCR expression analysis of each Arabidopsis insertional mutations. (*) represents strong or Wild-type like band, $(* *)$ represents full silencing, and $(* * *)$ represents down regulation. Lines without an asterisk indicate no data to date.

\begin{tabular}{|l|l|l|l|}
\hline AGI code & Name & Line & Used in Publication \\
\hline At1g02170 & AtMC1 & GABI_096A10** & Coll et al. 2010 \\
\hline & & Salk_002986* & \\
\hline At4g25110 & AtMC2 & SALK_009045** & $\begin{array}{l}\text { van Baarlen 2007, Coll et al. } \\
2010\end{array}$ \\
\hline At5964240 & AtMC3 & GABI_545D06* & \\
\hline At1g79340 & AtMC4 & Sail_856_D05** & Watanabe and Lam 2011 \\
\hline At1979330 & AtMC5 & SALK_145461C & \\
\hline At1g79320 & AtMC6 & SALK_063453** & \\
\hline & & SALK_006679 & \\
\hline At1g79310 & AtMC7 & SALK_127688** & \\
\hline At5904200 & AtMC9 & SALK14** & van Baarlen 2007 \\
\hline & & GK540** & \\
\hline
\end{tabular}

Table 3.2

AtMCs highest expression in various developmental stages, tissues and in response to inductive stimulus. Data collected from Genevestigator

\begin{tabular}{|c|c|c|c|}
\hline $\begin{array}{c}\text { AtMC } \\
\text { gene }\end{array}$ & $\begin{array}{c}\text { Developmental stage } \\
\text { where most highly } \\
\text { expressed }\end{array}$ & $\begin{array}{c}\text { Anatomical tissue where most highly } \\
\text { expressed }\end{array}$ & $\begin{array}{c}\text { Stimulus treatment where most highly } \\
\text { expressed }\end{array}$ \\
\hline 1 & Young Flower & Pollen & Cycloheximide, NAA+FLG \\
\hline 2 & Young Flower & Adult Leaves & Drought, Hypoxia \\
\hline 3 & Young Flower & Root Phloem & NAA+FLG, Hypoxia \\
\hline 4 & Seedling & Lateral Roots & Salicylic acid, IAA \\
\hline 5 & Mature Siliques & Lateral Roots & Cold, Drought \\
\hline 6 & Flowers and Siliques & Lateral Roots, Root Phloem & MeJa \\
\hline 7 & Young Rosette & Endoderm, Root Phloem & Clycloheximide, NAA+FLG \\
\hline 8 & Young Flower & Adult Leaves & Heat, MeJa \\
\hline 9 & Mature Siliques & Root Xylem & \\
\hline & & & \\
\hline
\end{tabular}


A.)

B.)

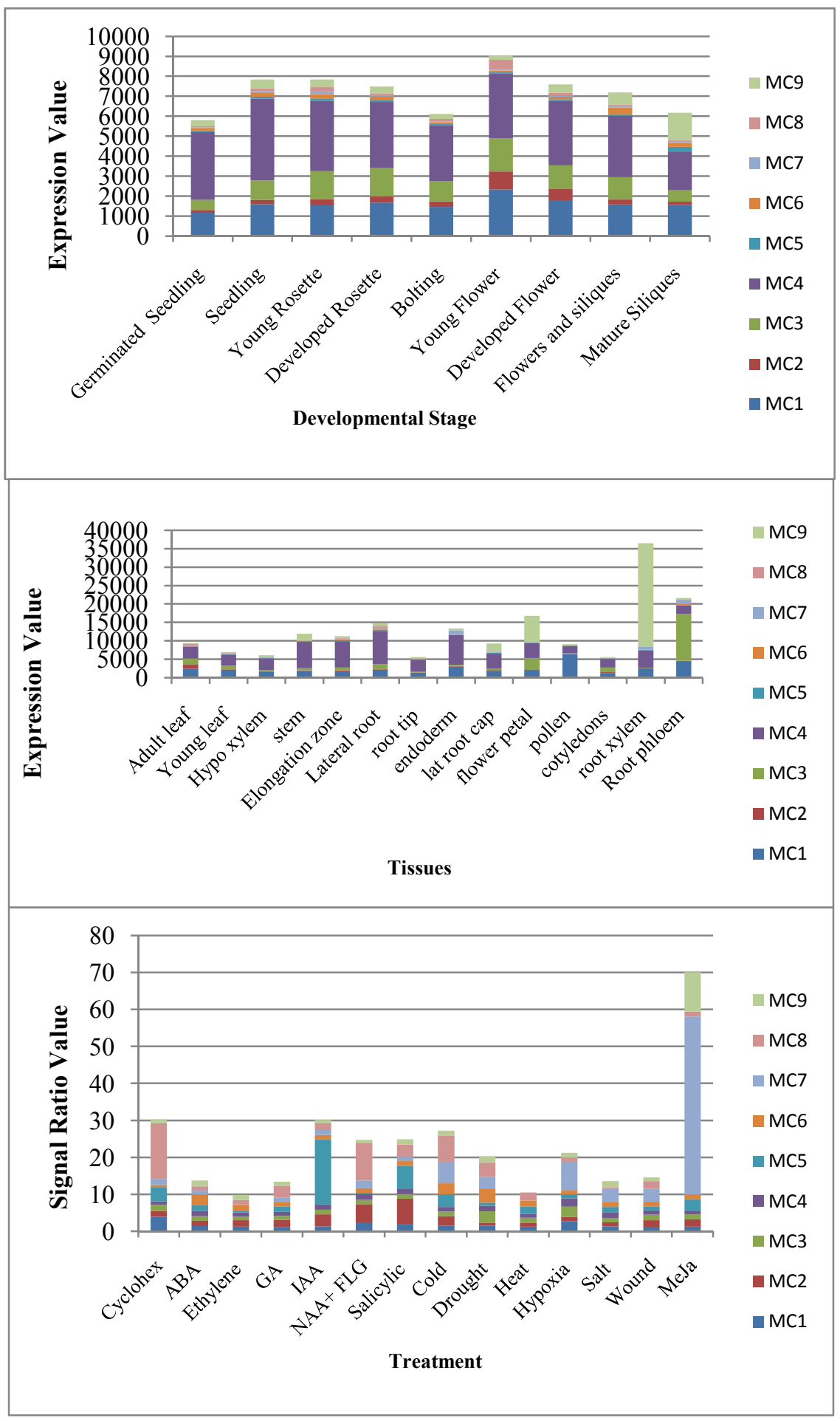

Figure 3.1 Expression Analysis of AtMC1-9. A, Developmental expression. B, Anatomical expression. $C$, Expression in response to stimulus treatment. 


\subsection{Reporter gene analysis of the $A t M C$ gene family}

Sequence alignment showed perfect matches for $A t M C$ s $1,2,4,5,8$ and 9 constructs. AtMC3 and 7 were not successfully amplified and AtMC6 had a single mutation of an adenine to guanine. The mutation was located in the promoter region approximately $300 \mathrm{bp}$ upstream from the ATG start codon of the gene. Due to its location in the promoter, it was determined that $M C 6$ could progress to the transformation stage back into Arabidopsis. The constructs containing AtMC1, AtMC2, AtMC5, AtMC6 and AtMC8 were transformed into Arabidopsis T1 plants and were inspected for localization of the GUS signal. AtMClwas expressed in both the leaf tissue and vasculature (Figure 3.2a), AtMC2 was observed at the tips of vascular tissue in leaves (Figure 3.2b), and $A t M C 8$, to a small degree, appeared in leaf tissue (Figure 3.2h). AtMC5 was expressed in trichomes and in leaf tissue where vascular patterns diverged, along with being expressed in pollen grains within an anther, seeds within a mature silique, and in developing seeds in an embryo (Figure 3.2c-g).

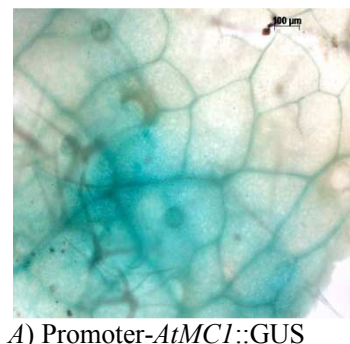

A) Promoter-AtMC1::GUS

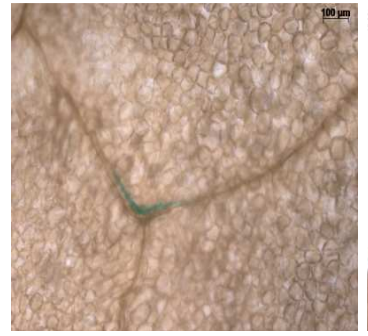

E) Promoter-AtMC5::GUS

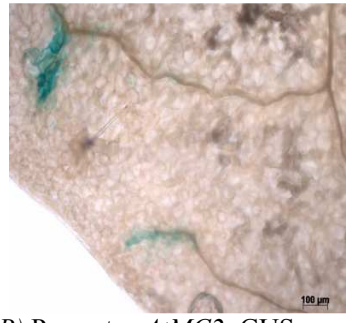

B) Promoter-AtMC $2:: \mathrm{GUS}$

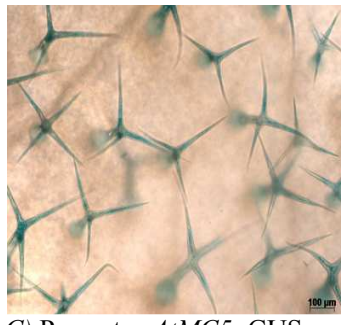

C) Promoter-AtMC5::GUS

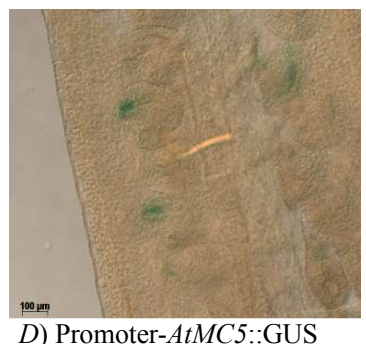

D) Promoter-AtMC5::GUS

Figure 3.2: Expression of promoter::gene::GUS constructs in Arabidopsis. Pictures depict expression of $A t M C 1, A t M C 2, A t M C 5$, and $A t M C 8$ in various plant tissues. 
3.4 Functional characterization of the AtMC gene family by reverse genetic approaches

There were no statistical differences between the mutants and Wild-type for the size of the rosette, the leaf number per rosette, or in the proportion of senescing leaves. Five of the mutant lines did show significantly different development than the wild type. Significant differences were observed in leaf width, in stem height and bolting time (data not shown) (Figure 3.3). These differences are summarized in Table 3.3.

Table 3.3

Mutant lines with statistically significant differences in rosette and stem development and bolting time

\begin{tabular}{|c|c|}
\hline Mutant & Characteristic with significantly different phenotype \\
\hline$m c 6-2$ & Smaller leaf number \\
\hline$m c 6-2$ & Smaller stem height \\
\hline$m c 9-2 m c 4$ & Smaller stem height \\
\hline$m c 9-1 m c 1-1$ & Smaller rosette leaf width \\
\hline$m c 2$ & Faster bolting time \\
\hline$m c 9-2$ & Slower bolting time \\
\hline
\end{tabular}




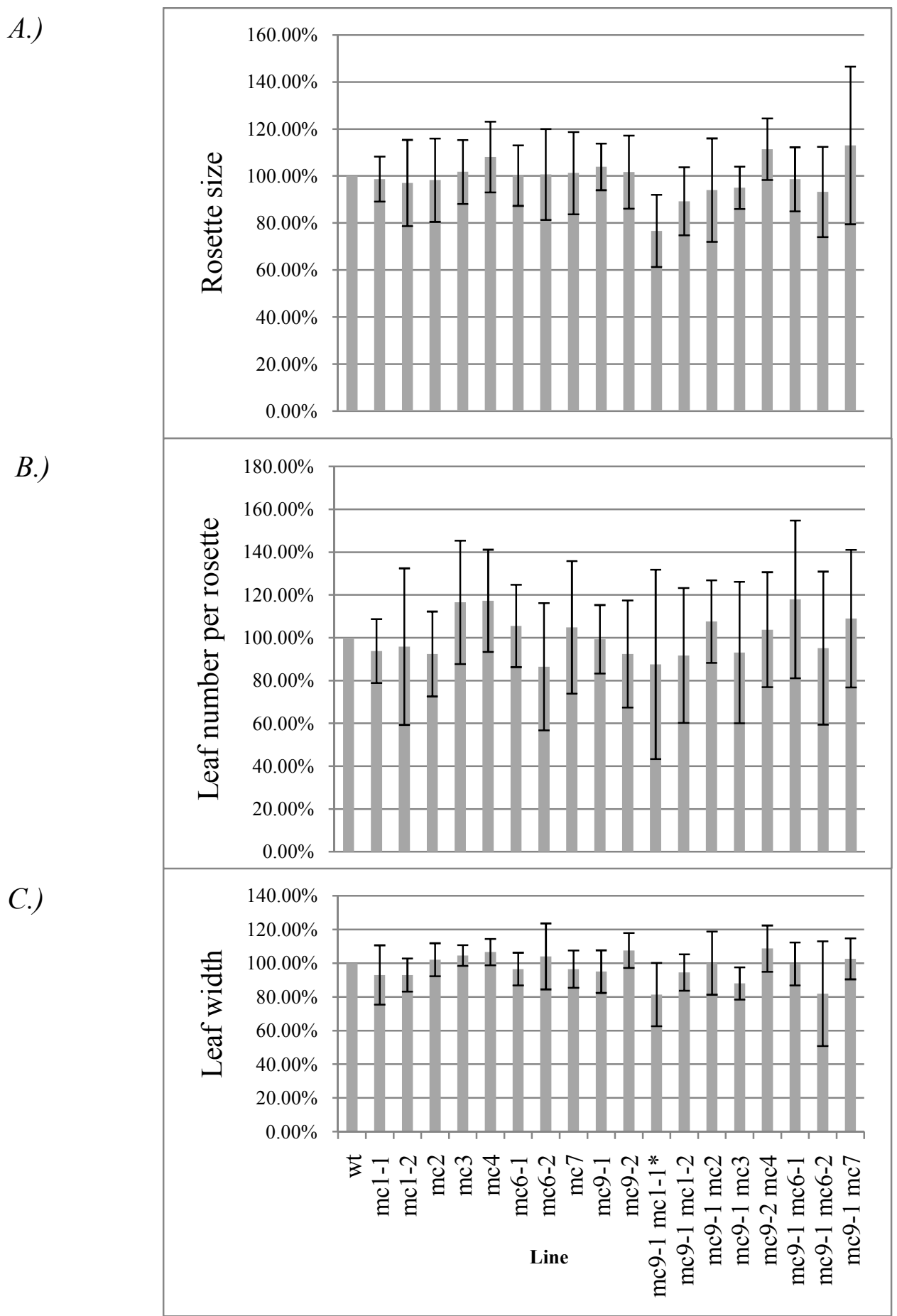


D.)

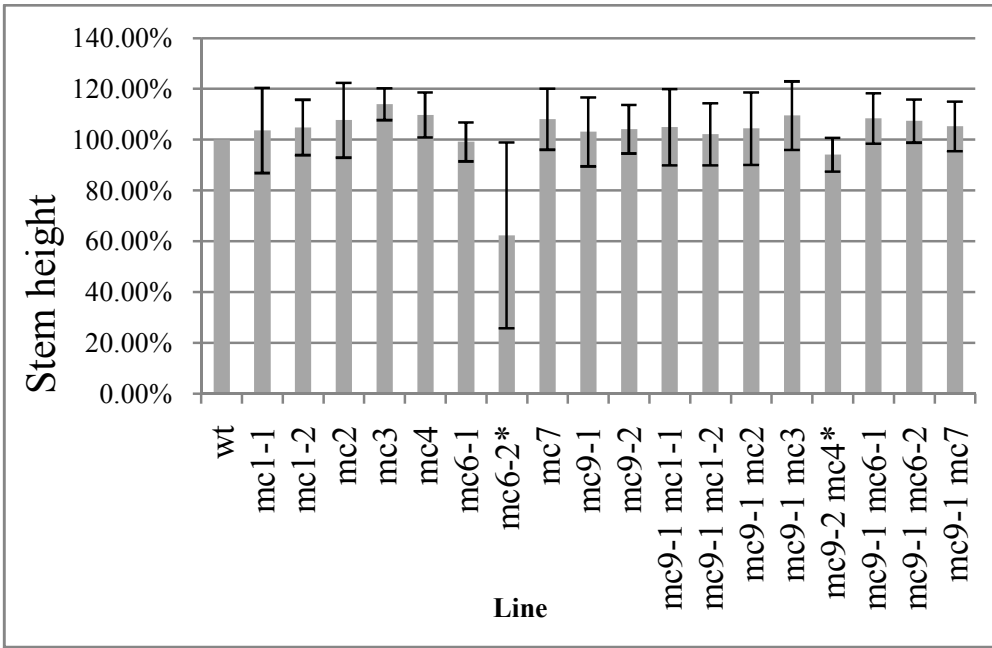

E.)

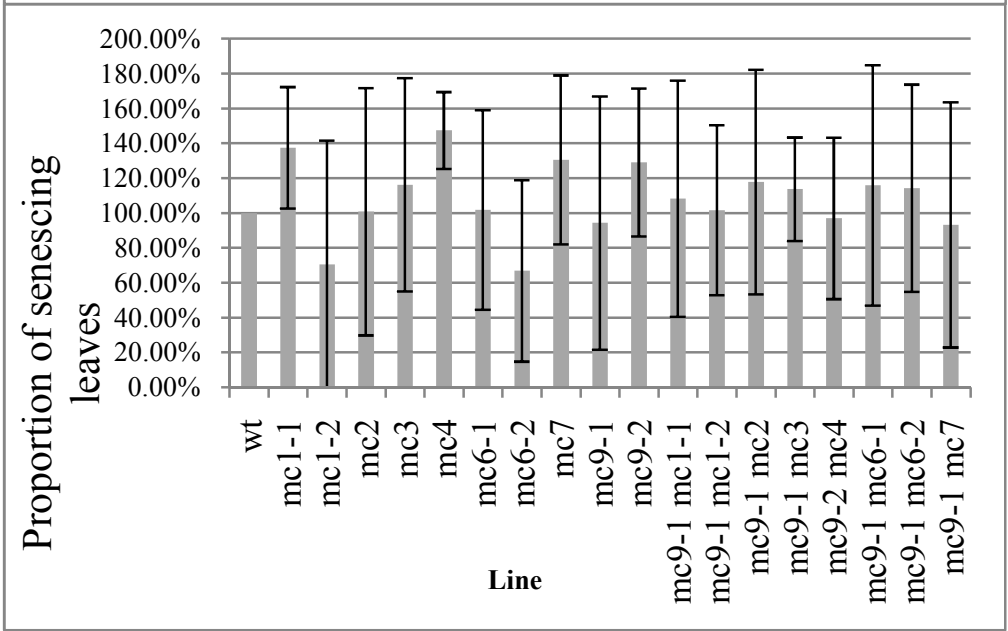

Figure 3.3: Morphological changes in AtMC single and double mutants. Data is presented as percentages of the mean value for each mutant line in comparison to the Wild-type (wt) mean value. Significant differences were analyzed using a t-test with a pvalue of 0.05 and are marked with an asterisk $(*) . A$, The size of the rosette was analyzed by measuring the rosette length from the tip of the longest leaf to the tip of the leaf directly horizontal to it. $B$, The number of leaves per rosette was counted. All leaves that were not fully degraded were scored as one individual leaf. $C$, The width of the leaves was analyzed by measuring the width of each leaf perpendicularly to the leaf petiole, at the middle of the leaf. The leaf per rosette with the largest width was recorded. $D$, The height of the main stem was measured from the base of the rosette to the top of the stem. $E$, The number of leaves showing any amount of senescence was noted per rosette per plant and the number of leaves per rosette was recorded. Next, for each plant, the number of leaves showing senescence was divided by the total number of leaves per rosette. This yielded a percentage of leaves which showed senescence per plant per mutant. This number was then used to determine the percentage value from the Wild-type mean as stated above. 


\section{Discussion}

Following the discovery that caspases play a role in animal PCD, homologous proteases like metacaspases (MCs) were identified in plants and other organisms. Even though caspases and MCs may be structurally homologous, they do not share functional homology. To date, the function of MCs in plants is still unknown. The nine MC genes of Arabidopsis were studied in this project in order to try and determine the function of AtMCs in various growth stages including plant PCD. The information learned from this project could be applied to other plants as well, such as Populus spp., spruce, and wheat and rice in agricultural systems. All of these plants, except spruce, have fully sequenced genomes allowing for more efficient interspecific MC sequence comparison.

In order to help elucidate the function $\mathrm{MC}$ genes play in plants, this project utilized expression analysis and reverse genetics. Based on in silico expression analysis, all AtMC genes are expressed in developmental stages ranging from seedling, rosette, stem, flower and silique maturation (Figure 3.1a). This data was further supported by promoter::gene:::GUS experiments. Transformed Arabidopsis plants containing these constructs showed that AtMC expression is indeed present in leaves, leaf vasculature, pollen, and siliques, along with trichomes and during what is believed to be embryo suspensor development in the siliques (Figure 3.2a-h). If indeed this expression represents embryo development, these findings support previous data from two publications where a type II metacaspase in $P$. abies was down-regulated resulting in a decrease in PCD in cells of the embryo suspensor (Suarez et al. 2004), and supports data which suggests the possibility that MCs may be involved in P. abies PCD affecting pattern formation during embryogenesis (Bozhkov et al. in 2005). The reporter gene in this project was detected in mature siliques, though this expression was confined to small localized areas throughout the tissue within some seeds (Figure 3.2g). Reporter gene expression was also detected in some pollen grains within the developing anthers (Figure 3.2g-h). Our result suggests that PCD could be involved during seed and pollen development. 
In silico expression analysis suggested that AtMC genes are not only expressed during various developmental stages, but in individual tissues as well, including leaves, stems, roots, flowers and in the vasculature (Figure 3.1b). Transformed Arabidopsis plants in this experiment showed that $\mathrm{MC}$ expression is indeed present in leaf tissue, in pollen and in leaf vasculature (Figure 3.2a-h) Using Arabidopsis $m c$ single and double mutants, the function of MCs in rosette, leaf, and stem development was studied. Based on the data collected during these functional analyses, significant differences between the mutants and Wild-type were observed in both leaves and stems (Table 3.3, Error! Reference source not found.) in five of the nine mutants. According to this data, it is possible that $A t M C 1,2,4,6$ and 9 may be directly involved in leaf or stem development in Arabidopsis.

Even though significant phenotypic differences were not observed for the remaining mutants, roles for these genes during development or in PCD are possible. One reason for a lack of an obvious phenotype in the remaining $m c$ mutants could be contributed to the need of correct identification of environmental or external conditions to expose the phenotypic differences. It is possible that at least some of the AtMC genes are pseudogenes. This possibility may be supported by the fact that MC type II are completely absent in two algae species (Cambra et al. 2010). This means that only homologues of AtMC1-3 are completely conserved in the algae and that AtMC4-9 may play dispensable roles in plants. However, because all MC genes were expressed during the expression analysis of this study, and because algae are much simpler than higher plants, this alternative seems unlikely. The results from this study, together with the published work on the type II MCs have clearly shown that MCs do play some role in higher plant development.

Although it is unlikely that the AtMC genes are pseudogenes, gene redundancy due the close evolutionary relationship between some of the AtMCs (Figure 1.1, Table 2.2) may account for the lack of significantly different mutant phenotypes for the majority of the mutations. To my knowledge, this is the first report where significant 
differences between $m c$ mutants and Wild-type have been reported in Arabidopsis. Other publications have failed to reveal any major alterations in the growth and development of $m c$ mutants (Coll et al. 2010, He et al, 2008, Wantanabe and Lam 2011). According to the expression analysis from this project, $A t M C 1$ and $A t M C 4$ show high expression values during development and in various anatomical features, suggesting they may take over the role of other genes. Of course, with the consistently high levels of expression seen in AtMC4 it may not be completely reasonable to focus attention on the analysis of this gene since it could have other roles deviating from development or PCD. It is also possible that with its ubiquitous expression level throughout the plant, AtMC4 is playing a role in redundancy leading to the lack of a phenotype. It would be interesting to see if any significant developmental differences exist between an atmcl atmc4 double mutant. Also, to better study the roles of AtMC genes, crosses producing plants with more than two MC silenced genes per plant should be analyzed. Due to the interest of this lab in AtMC9 and xylem formation, it would be interesting to analyze the phenotype of the triple mutant $\mathrm{mcl} \mathrm{mc4} \mathrm{mc} 9$. Other possible triple mutants of interest according to the expression analysis data would be $m c 1 m c 3 m c 4, m c 2 m c 4 m c 9$, and $m c 3 m c 4 m c 9$. Even with the support of this expression data, the other AtMC genes should not be ignored since even low expression levels located in either specific tissue or within certain cell types could be important, and the lack of a high level of expression in pooled microarray database does not indicate that other MCs are not important.

Even though AtMCs 1-4, and 9 may be the key players in development and have the highest expression in various tissues, according to this project the other $A t M C$ s appear to be most affected by stimulus treatments. As stated above, mutant plants which have been crossed to provide more than two silenced genes per plant could provide valuable information on the role of the genes more highly expressed under stimulus treatments. Unfortunately, there is no chance to create mutant crosses between these genes due to their close proximity to each other on the chromosome (Table 2.2). Previous studies have shown that AtMC 8 is highly induced by stress treatments such as $\mathrm{UV}$, and $\mathrm{H}_{2} \mathrm{O}_{2}(\mathrm{He}$ et al 
2007). Data collected from database expression analysis in this project supported this hypothesis by showing high expression levels of AtMC8 in plants treated with cycloheximide, auxin and cold. Surprisingly, in one transformed Arabidopsis plant during the project, which contained the AtMC8 promoter::gene::GUS construct, expression was observed around small areas of vasculature in leaf tissue (Figure 3.2h). This could be due to unintentional wounding of the plant tissue prior to analysis, GUS leakage, or it could suggest that $A t M C 8$ plays more of a role during development than was previously believed. In the future, it would be interesting to study the phenotype of AtMCs while under external stimuli after application of exogenous plant hormones, application of stress factors known to promote expression in the various genes (Figure 3.1c), or under pathogen infection. Also, transformed plants containing the AtMCpromoter::AtMCgene::GUS constructs could be placed under various stress treatments, or grown with the addition of exogenous hormones, and the effect on GUS expression could be observed.

When the database expression data is combined, it suggests that each MC may have a role to play in plants, and that $\mathrm{MC}$ genes not strongly involved in natural plant growth may be induced by external conditions. Due to their structural similarity to caspases, it is believed that MCs may play a role in PCD. It appears from the results of this project that AtMC genes alone may not contribute to PCD in plants as much as was previously believed and that there are other players involved in the process. This would not be surprising since biology is complex and in many systems multiple interconnecting components are necessary to allow for full functionality of the organism. It is possible that AtMC genes may have a complex system among themselves; a system which acts as a sort of checks and balances to provide PCD stability throughout the lifespan of the plant. This idea is supported by a recent study which showed that AtMC1 and AtMC2 acted antagonistically with $A t M C 1$ positively regulating PCD and $A t M C 2$ negatively regulating it during pathogen attack (Coll et al 2010). It is possible that not one but a combination of all these suggested processes contribute to Arabidopsis PCD in various 
degrees depending on internal and external conditions. Yet another possibility is that AtMCs do not play any role in PCD which is ongoing during normal growth and development.

\section{1 $\quad$ Future work}

On a broad scale, obtaining the full genome sequence of spruce will give more insight into the roles of MCs by providing another organism in which to study. The study of Poplar and spruce together could lead to significant discoveries regarding the role of MCs in xylem development since they are woody plants containing a large amount of xylem. Also, different plants contain different numbers of MC genes, for example, there are nine in Arabidopsis and four in Populus. Within the ancestors of modern plants, cyanobacteria, there are at least $58 \mathrm{MC}$ genes within 33 different species which have been identified (Jiang et al. 2010). The difference in number may or may not influence the way in which MCs interact and the mechanisms behind their roles in each species. The more plants species to be fully sequenced, the more information science can obtain regarding how $\mathrm{MC}$ genes have evolved in different species over time, their various roles, and how they function both similarly and differently among species today. This knowledge could allow increased production and conservation techniques in both the forestry and agricultural sectors providing solutions to some of the world's most challenging problems such as declining resources, the need for increased productivity, and yield loss due to pathogen attack.

On a more detailed scale, the expression work performed during this thesis could be continued in a variety of ways. To date, only AtMC1, 2, 5, 6 and 8 were transformed and observed for GUS expression. The remaining lines should be analyzed and future GUS analysis should include other tissues such as roots. After all AtMC constructs are transformed and all tissues are observed for GUS expression, the various expression patterns should be compared to provide insight to possible roles each AtMC may play. Another alternative for expression study could include In situ hybridization which may 
provide supporting information regarding the expression patterns of the AtMC genes. Since the GUS constructs also contained GFP, AtMC protein localization could be analyzed to give further insight and/or support into the function of each gene.

Future phenotyping projects could include the use of RNA interference (RNAi). Theoretically, RNAi would be able to silence anywhere from one to all nine genes at once without the logistical restrictions of genetic crosses. This technique was presently attempted in this laboratory for $A t M C 9$, and produced interesting results suggesting a function for $A t M C 9$ together with still unknown additional members of the $\mathrm{MC}$ gene family in the overall growth of the seedlings and secondary cell wall properties (Unpublished). RNAi can target genes that it was not designed to target and it is not always able to fully silence the genes of interest, thus a more gene specific technology such as artificial microRNA (amiRNA) analysis could be a better option.

Combining DNA analysis with proteomics could give a more detailed indication of the functions of AtMCs. Other proteases such as serine proteases and other cysteine proteases are believed to be involved in PCD. A vacuolar cysteine protease, along with an aspartic protease, has been shown to influence proto- and meta-xylem formation in barley through immunohistochemical staining (Runeberg-Roos \& Saarma1998). A yeast-twohybrid may be able to determine which enzymes may also be interacting with MCs.

Initiator caspases contain two domains, a death effector domain (DED) and a caspase recruitment domain (CARD), both of which are located in the prodomain. Caspases which contain these domains can autoprocess while caspases without the prodomain must use another protease for activation (Lee et al. 2010). The yeast MC type 1 gene (Ycal), like all other MC type I genes, contains a prodomain, but lacks a DED or CARD motif (Lee et al. 2010), while MC type II genes do not contain any prodomain (Cambra et al. 2010). Currently, it is unknown how MCs in yeast, or other fungi, plants or protists, are activated (Carmona-Gutierrez et al. 2010). Future work could shed some insight on how autoprocesseses in both types of MCs is initiated. 
According to database expression analysis in this project and from previous microarray data in Poplar (Courtois-Moreau 2009), AtMC9 is most dominantly expressed in root xylem. If AtMC9 does play a direct role in xylem PCD, it could be expected that the mutants would show a reduced rate of PCD causing xylem to develop later than in the wild-type. It is unlikely that full mutations in these genes would completely halt PCD development, though. If this were the case, xylem would not develop and thus the mutants would obtain a lethal-like phenotype. Electron microscopy analysis of cross sectioned roots and hypocotyls could provide data on xylem development and PCD in Arabidopsis $m c 9$ mutants. An alternative for $m c 9$ study would be the development of assays which would identify xylem specific mutants. Even though treachery elements (TEs) are the current focus for increasing xylem biomass, it may not be advantageous to the health of the plant to manipulate the rate at which these cells undergo PCD. For example, altered TE development could lower the rate of water transportation, decrease the overall growth rate, or produce plants that are more sensitive to drought. Ultimately we are interested in manipulating the structural components of xylem, the fiber cells, rather than TEs. First, though, the promoters of fiber genes need to be isolated. After identification of these promoters, work can turn to increasing biomass via fiber manipulation rather than TE manipulation.

The work done in this thesis was only a small part of the bigger picture. After determining the role of AtMCs, the next step will be to elucidate the other key players in the signalling pathways and determine the mechanisms behind how they all interact together. To do this, other components need to be identified such as upstream transcription factors which can act as either activators or repressors and the cis-elements of AtMCs, along with discovering which substrates besides Tudor staphylococcal nuclease (Sundström et al. 2009) MCs act on. Other genes involved in PCD could to be studied to determine possible connections between them and AtMCs. Potential candidates could be ACAULIS5 (ACL5), whose mutation has been shown to cause premature death 
in xylem, (Muñiz 2008) and VASCULAR-RELATED NAC-DOMAIN6 (VND6), a regulator of xylem PCD (Ohashi-Ito et al. 2010)

\subsection{Conclusion}

In conclusion, the role of AtMCs in Arabidopsis PCD is still unclear. Even after determining where each AtMC protein is expressed within the plant, we still need to discover if AtMCs play a direct role in PCD, if they play a role but interact with other players, or if they do not have a role in PCD at all and have another role entirely. It appears that AtMC genes do play a role in PCD due to their similar structure to caspases, and the data collected to date. Judging by the lack of a strong mutant phenotype, it is likely that they do not act alone, but interact with both each other, and other components, creating a complex interaction whose mechanism is modified depending on different internal and external conditions. The key is to identify those players and to develop a hypothesis on how the players interact in order to regulate PCD so effectively. 


\section{References}

The Arabidopsis Genome Initiative. 2000. Analysis of the genome sequence of the flowering plant Arabidopsis thaliana. Nature. 408:796-815.

Aravind L, Koonin EV. 2002. Classification of the Caspase-Hemoglobinase Fold:Detection of New Families and Implications for the Origin of Eukaryotic Separins. PROTEINS: Structure, Function, and Genetics. 46:355-367.

Barrett AJ, Rawlings ND 2001. Evolutionary Lines of Cysteine Peptidases. Biological Chemistry. 382(5):727-733.

Beers EP, Woffenden BJ, Zhao C. 2000. Plant proteolytic enzymes: possible roles during programmed cell death. Plant Molecular Biology. 44:399-415.

Beers EP, Jones AM, Dickerman AW 2004. The S8 serine, C1A cysteine and A1 aspartic protease families in Arabidopsis. Phytochemistry. 65:43-58.

Belenghi B, Romero-Puertas MC, Vercammen D, Brackenier A, Inzé D, Delledonne B, Van Breusegem F. 2007. Metacaspase Activity of Arabidopsis thaliana is Reguated by S-Nitroylation of a Critical Cysteine Residue. Journal of Biological Chemistry. 282 (2):1352-1358.

Benfey RN, Protopapas AD. 2005. Genomics. $1^{\text {st }}$ ed. Upper Saddle River (NJ): Pearson Education, Inc.

Berg JM, Tymoczko JL, Stryer L. 2002 Biochemistry $5^{\text {th }}$ edition. New York (NY): Freemand and Company.

Bonneau L, Ge Y, Drury GE, Gallois P. 2008. What happened to plant caspases? Journal of Experimental Botany. 59(3):491-499.

Bozhkov PV, Suarez MF Filonova LH, Daniel G, Zamyatnin AA, Rodriguez-Nieto S, Zhivotovsky B, Smertenko A. 2005. Cysteine protease mcII-Pa executes programmed cell death during plant embryogenesis. PNAS 102(40):14463-14468.

Brown TA. 1995. Gene Cloning: An introduction. $3^{\text {rd }}$ Ed. London: Chapman \& Hall.

Cambra I, Garcia FJ, Martinez M. 2010. Clan CD of cysteine peptidases as an example of evolutionary divergences in related protein families across plant clades. Gene. 449:59-69.

Carmona-Gutierrez D, Fröhlich K-U, Kroemer G, Madeo F. 2010. Metacaspases are caspases. Doubt no more. Cell Death and Differentiation. 17:377-378. 
Castillo-Olamendi L, Bravo-García A, Morán J, Rocha-Sosa M, Porta H. 2007. AtMCP1b, a chloroplast-localised metacaspase, is induced in vascular tissue after wounding or pathogen infection. Functional Plant Biology. 34:1061-1071.

Coffeen WC, Wolpert TJ. 2004. Purification and characterization of serine proteases that exhibit caspase-like activity and are associated with programmed cell death in Avena sativa. The Plant Cell. 16:857-873.

Coll N S, Vercammen D, Smidler A, Clover C, van Breusegem F, Dangl J L, Epple P. 2010. Arabidopsis Type I Metacaspase Controls Cell Death. Science. 30(6009):1393-1397.

Cooper GM. 2000. The Cell: A Molecular Approach. $2^{\text {nd }}$ edition. Sunderland (MA): Sinauer Associates, Inc.

Courtois-Moreau C, Pesquet E, Sjödin A, Muñiz L, Bollhöner B, Kaneda M, Samuels L, Jansson S, Tuominen H. 2009. A unique program for cell death in xylem fibers of Populus stem. The Plant Journal. 58:260-274.

Elinor EE, Fass D, Bibi E. 2009. How intramemrane proteases bury hydrolytic reactions in the membrane. Nature. 459:371-378.

Gabaldón C, Gómez Ros LV, Pedreño MA, Barceló A R. 2004. Nitric oxide production by the differentiation xylem of Zinnia elegans. New Phytologist. 165:121-130.

García-Lorenzo M. 2007. The Role of Proteases in Plant Development. Doctorial Dissertation: Department of Chemistry. Umeå University, Umeå Sweden.

Gelvin SB. 2010 Plant Proteins Involved in Agrobacterium-Mediated Genetic Transformation. Annual Review of Phytopathology. 48:3.1-3.24.

González IJ, Desponds C, Schaff C, Mottram C, Fasel N. 2007. Leishmania major metacaspase can replace yeast metacaspase in programmed cell death and has argininie- specific systeine peptidase activity. International Journal of Parasitology. 37:161-172.

Greenberg JT. 1996. Programmed cell death: A way of life for plants. Proceedings of the National Academy of Science. 93:12094-12097.

Hao L, Goodwin PH, Hsiang T. 2007. Expression of a metacaspase gene of Nicotiana benthamiana after inoculation with Colletotrichum destructivum of Pseudomonas syringae pv. tomato, and the effect of silencing the gene on the host response. Plant Cell Reports. 26(10):1879-1888. 
Hatsugai N, Kuroyanagil M, Yamanda K, Meshi T, Tsuda S, Kondo M, Nishimura M, Hara-Nishimura I. 2004. A Plant Vacuolar Protease, VPE, Mediates VirusInduced Hypersensitive Cell Death. Science. 305(5685):855-858.

Hays J B. 2002. Arabidopsis thaliana, a versatile model system for study of eukaryotic genome-maintenance functions. DNA Repair. 1(8):579-600.

He R, Drury GE, Rotari VI, Gordon A, Willer M, Tabasum F, Woltering EJ, Gallois P. 2007. Metacaspase- 8 modulates programmed cell death induced by UV and $\mathrm{H} 2 \mathrm{O} 2$ in Arabidopsis. Journal of Biological Chemistry. 283:774-783.

Hoeberichts FA, ten Have A, Woltering EJ. 2003. A tomato metacaspase gene is upregulated during programmed cell death in Botrytis cinerea-infected leaves. Planta. 217(3):517-522.

Hudson PJ, Razanatsoa J, Field TS. 2010. Early vessel evolution and diversification of wood functions: Insights from Malagasy Canellales. American Journal of Botany. 97(1):80-93.

Jiang Q, Qin S, Wu Qing-yu. 2010. Genome-wide comparative analysis of metacaspases in unicellular and filamentous cyanobacteria. BMC Genomics. 11:198.

Jones A, Reed R, Weyers J. 2003. Practical Skills in Biology $3^{\text {rd }}$ Edition. United Kingdom: Pearson Education Limited.

Krysan PJ, Young JC, Sussman MR. 1999. T-DNA as an Insertional Mutagen in Arabidopsis. Plant Cell. 11:2283-2290.

Kuroyanagi M, Yamada K, Hatsugai N, Kondo M, Nishimura M, Hara-Nishimura I. 2005. Vacuolar Processing Enzyme is Essential for Mycotoxin-induced Cell Death in Arabidopsis thaliana. Journal of Biological Chemistry. 280(38):3291432920.

Lee REC, Brunette S, Puente LG, Megeney LA. 2010. Metacaspase Yca1 is required for clearance of insoluble protein aggregates. PNAS. 107(30):13348-13353.

Love AJ, Milner JJ, Sadanandom A. 2008. Timing is everything: regulatory overlap in plant cell death. Trends in Plant Science. 13(11):589-595.

Madeo F, Herker E, Maldener C, Wissing S, Lächelt S, Herlan M, Fehr M, Lauber K, Sigrist SJ, Wesselborg S, Fröhlich KU. 2002. A caspase-related protease regulates apoptosis in yeast. Molecular Cell. 9(4):911-917. 
Mandels M, Kostick J, Parizek R. 1971. The use of adsorbed cellulose in the continuous conversion of cellulose to glucose. Journal of Polymer Science Part C: Polymer Symposia. 36(1):445-459.

Mellerowicz EJ, Baucher M, Sundberg B, Berjan W. 2001. Unravelling cell wall formation in the woody dicot stem. Plant Molecular Biology. 47:239-274.

Millonig G. 1961. Advantages of a phosphate buffer for osmium tetroxide solutions in fixation. Journal of Applied Physiology. 32:1637.

Muñiz L, Minguet EG, Singh SK, Pesquet E, Vera-Sirera F, Moreau-Courtois CL Carbonell J, Blázquez M.A, Tuominen H. 2008. ACAUSIS5 controls Arabidopsis xylem specification through the prevention of premature cell death. Development. 135:2573-2582.

Nieminen KM, Kauppinen L, HelariuttaY. 2004. A weed for wood? Arabidopsis as a genetic model for xylem development. Plant Physiology. 135:653-659.

Nigam P, Singh D. 1995. Enzyme and microbial systems involved in starch processing. Enzyme and Microbial Technology. 17(9):770-778.

Ohashi-Ito K, Oda Y, Fukuda H. 2010 Arabidopsis VASCULAR-RELATED NACDOMAIN6 directly regulates the genes that govern programmed cell death and secondary wall formation during xylem differentiation. The Plant Cell. 22:34613473.

Pilcher K, Fey, Gaudet P, Kowal AS, Chisholm RL. 2007. A reliable general purpose method for extracting genomic DNA from Dictyostelium cells. Nature Protocols. 2:1325-1328.

Quaedvlieg NEM, Schlaman HRM, Admiraal PC, Wijting SE, Stougaard J, Spaink HP. 1998. Fusions between green fluorescent protein and $\beta$-glucuronidase as sensitive and vital bifunctional reporters in plants. Plant Molecular Biology. 38:861-873.

Riedl S J, Shi Y. 2004. Molecular mechanisms of caspase regulation during apoptosis. Nature Reviews: Molecular Cell Biology. 5:897-907.

Ryan A R. 1990. Protease Inhibitor in Plants: Genes for Improving Defenses Against Insects and Pathogens. Annual Review of Phytopathology. 28:425-49

Runeberg-Roose P, Saarma M. 1998 Phytepsin, a barley vacuolar aspartic proteinase, is highly expressed during autolysis of developing tracheary elements and sieve cells. The Plant Journal. 15(1):139-145. 
Skog KE, Nicholson GA. 2000. Carbon sequestration in wood and paper products. A Joyce, and RA Birdsey. The impact of climate change on America's forests. USDA Forest Service, Rocky Mountain Research Station, General Technical Report RMRSGTR-59. p.79-88.

Solomon M, Belenghi B, Delledonne M, Menachem E, Levine A. 1999. The Involvement of Cysteine Proteases and Protease Inhibitor Genes in the Regulation of Programmed Cell Death in Plants. The Plant Cell. 11:431-443.

Suarez MF, Filonova LH, Smertenko A, Savenkov EI, Clapham DH, von Arnold S, Zhivotovsky B, Bozhkov PV. 2004. Metacaspase-dependandt programmed cell death is essential for plant embryogenesis. Current Biology. 14:339-340R339R340.

Sundström JF, Vaculova A, Smertenko AP, Savenkov EI, Golovko A, Minina E, Tiwari BS, Rodriguez-Nieto S, Zamyatnin AA Jr, Välineva T, Saarikettu J, Frilander MJ, Suarez MF, Zavialov A, Ståhl U, Hussey PJ, Silvennoinen O, Sundberg E, Zhivotovsky B, Bozhkov PV. 2009. Tudor staphylococcal nuclease is an evolutionarily conserved component of the programmed cell death degradome.Nature Cell Biology. 11(11):1347-1354.

Thornberry N.A, Lazebnik Y. 1998. Caspases: Enemies Within. Science. 281(5381):1312-1316.

Turner S, Gallois P, Brown D. 2007. Tracheary Element Differentiation. Annual. Review of Plant Biology. 58:407-33.

Tuskan A., et al. (2006). The Genome of Black Cottonwood, Populus trichocarpa (Torr. \& Gray). Science 313(5793):1596-1604.

Uren AG, O'Rourke K, Aravind LA, Pisabarro MT, Seshagiri S, Koonin EV, Dixit VM. 2000. Identification of Paracaspases and Metacaspases: Two Ancient Families of Caspase-like Proteins, One of which Plays a Key Role in MALT Lymphoma. Molecular Cell. 6:961-967.

van Baarlen P, Woltering EJ, Staats M. 2007. Histochemical and genetic analysis of host and non-host interactions of Arabidopsis with three Botrytis species: an important role for cell death control. Molecular Plant Pathology. 8(1):41-54.

Van der Hoorn RAL. 2008 Plant Proteases: From phenotypes to molecular mechanisms. Annual Review of Plant biology. 59:191-223. 
Vercammen D, van de Cotte B, De Jaeger G, Eeckhout D, Casteels P, Vandepoele K, Vandenberghe I, Van Beeumen J, Inzé D, Van Breusegem F. 2004. Type II Metacaspases Atmc4 and Atmc9 of Arabidopsis thaliana Cleave Substrates after Arginine and Lysine. The Journal of Biological Chemistry. 279(44):45329-45336.

Vercammen D, Belenghi B, van de Cotte B, Beunens T, Gavigan J-A, De Rycke R, Brackenier A, Inzé D, Harris JL, Van Breusegem F. 2006. Serpin1 of Arabidopsis thaliana is a Suicide Inhibitor for Metacaspase 9. Journal of Molecular Biology. 364:625-636.

Vercammen D, Declercq W, Vandenabeele P, Van Breusegem F. 2007. Are metacasases caspases? The Journal of Cell Biology. 179(3):375-380.

Watanabe N, Lam E. 2005. Two Arabidopsis Metacaspases AtMCP1b and AtMCP2b Are Arginine/Lysine-specific Cysteine roteases and Activate Apoptosis-like Cell Death in Yeast. The Journal of Biological Chemistry. 280(15):14691-14699.

Watanabe N, Lam E. 2011. Calcium-dependent activation and autolysis of Arabidopsis Metacaspase 2d. Journal of Biological Chemistry. Manuscript M110.194340/ Available at: http://www.jbc.org/content/early/2011/01/05/jbc.M110.194340.full.pdf+html

Woltering EJ, van der Bent A, Hoeberichts FA. 2002. Do Plant Caspases Exist? Plant Physiology. 130:1764-1769.

Woltering EJ. 2004. Death proteases come alive. TRENDS in Plant Science. 9(10):469472. 